\title{
Selective Placement of Bromide and Pinacolboronate Groups About a Tellurophene: New Building Blocks for Optoelectronic Applications
}

William Torres Delgado, ${ }^{1}$ Fatemeh Shahin, ${ }^{1}$ Michael Ferguson, ${ }^{1}$ Robert McDonald, ${ }^{1}$ Gang $\mathrm{He}^{2,{ }^{*}}$ Eric Rivard ${ }^{1, *}$

${ }^{1}$ Department of Chemistry, University of Alberta, 11227 Saskatchewan Drive, Edmonton, Alberta, Canada, T6G 2G2

${ }^{2}$ Center for Materials Chemistry, Frontier Institute of Science and Technology, Xi'an Jiaotong University, Xi'an, Shaanxi Province, 710054, P. R. China

\section{TABLE CONTENT:}

1. ${ }^{1} H,{ }^{13} C\left\{{ }^{1} H\right\}$ and ${ }^{11} B\left\{{ }^{1} H\right\} N M R$ Spectra

Figure S1.A) $\left.{ }^{1} \mathrm{H}, \mathrm{B}\right){ }^{13} \mathrm{C}\left\{{ }^{1} \mathrm{H}\right\}$ and $\left.\mathrm{C}\right){ }^{11} \mathrm{~B}\left\{{ }^{1} \mathrm{H}\right\}$ NMR Spectra of 2BTe

Figure S2.A) $\left.{ }^{1} \mathrm{H}, \mathrm{B}\right){ }^{13} \mathrm{C}\left\{{ }^{1} \mathrm{H}\right\}$ and $\left.\mathrm{C}\right){ }^{11} \mathrm{~B}\left\{{ }^{1} \mathrm{H}\right\}$ NMR Spectra of BTe

Figure S3.A) $\left.{ }^{1} \mathrm{H}, \mathrm{B}\right){ }^{13} \mathrm{C}\left\{{ }^{1} \mathrm{H}\right\}$ and C) ${ }^{11} \mathrm{~B}\left\{{ }^{1} \mathrm{H}\right\}$ NMR Spectra of B-Te-6-H

Figure S4.A) ${ }^{1} \mathrm{H}$ and B) ${ }^{13} \mathrm{C}\left\{{ }^{1} \mathrm{H}\right\}$ NMR Spectra of $\mathbf{H}-\mathrm{Te}-\mathbf{6 - H}$

Figure S5.A) ${ }^{1} \mathrm{H}$ and $\left.\mathrm{B}\right){ }^{13} \mathrm{C}\left\{{ }^{1} \mathrm{H}\right\}$ NMR Spectra of $\mathrm{Br}-\mathrm{Te}-6-\mathrm{Br}$

Figure S6.A) ${ }^{1} \mathrm{H}$ and $\left.\mathrm{B}\right){ }^{13} \mathrm{C}\left\{{ }^{1} \mathrm{H}\right\}$ NMR Spectra of $2 \mathrm{BrTe}$

Figure S7.A) ${ }^{1} \mathrm{H}$ and $\left.B\right){ }^{13} \mathrm{C}\left\{{ }^{1} \mathrm{H}\right\}$ NMR Spectra of BrTe

Figure S8.A) $\left.{ }^{1} \mathrm{H}, \mathrm{B}\right){ }^{13} \mathrm{C}\left\{{ }^{1} \mathrm{H}\right\}$ and C) ${ }^{11} \mathrm{~B}\left\{{ }^{1} \mathrm{H}\right\}$ NMR Spectra of B-TeBr${ }_{2}-\mathbf{6}-\mathbf{B}$

Figure S9.A) $\left.{ }^{1} \mathrm{H}, \mathrm{B}\right){ }^{13} \mathrm{C}\left\{{ }^{1} \mathrm{H}\right\}$ and $\left.\mathrm{C}\right){ }^{11} \mathrm{~B}\left\{{ }^{1} \mathrm{H}\right\}$ NMR Spectra of 4BS 
Figure S10.A) $\left.{ }^{1} \mathrm{H}, \mathrm{B}\right){ }^{13} \mathrm{C}\left\{{ }^{1} \mathrm{H}\right\}$ and C) ${ }^{11} \mathrm{~B}\left\{{ }^{1} \mathrm{H}\right\}$ NMR Spectra of a Mixture of BS and 2BS

Figure S11.A) $\left.{ }^{1} \mathrm{H}, \mathrm{B}\right){ }^{13} \mathrm{C}\left\{{ }^{1} \mathrm{H}\right\}$ and $\left.C\right){ }^{11} \mathrm{~B}\left\{{ }^{1} \mathrm{H}\right\}$ NMR Spectra of 4BSe

Figure S12.A) $\left.{ }^{1} \mathrm{H}, \mathrm{B}\right){ }^{13} \mathrm{C}\left\{{ }^{1} \mathrm{H}\right\}$ and $\left.\mathrm{C}\right){ }^{11} \mathrm{~B}\left\{{ }^{1} \mathrm{H}\right\}$ NMR Spectra of a Mixture of BSe and 2BSe

Figure S13.A) ${ }^{1} \mathrm{H}$ and $\left.B\right){ }^{13} \mathrm{C}\left\{{ }^{1} \mathrm{H}\right\}$ NMR Spectra of T-Te-6-T

Figure S14. ${ }^{1} \mathrm{H}$ NMR Spectrum of a Reaction Mixture containing $\mathrm{BrBTe}$ and $2 \mathrm{BrTe}$ in $\mathrm{CDCl}_{3}$

Figure S15. ${ }^{1} \mathrm{H}$ NMR Spectrum of a Reaction Mixture containing 3BTe and 2BTe in $\mathrm{CDCl}_{3}$

Figure S16. A) $\left.{ }^{1} \mathrm{H}, \mathrm{B}\right){ }^{13} \mathrm{C}\left\{{ }^{1} \mathrm{H}\right\}$ and C) ${ }^{11} \mathrm{~B}\left\{{ }^{1} \mathrm{H}\right\}$ NMR Spectra of B-Te6-B

Figure S17. A) $\left.{ }^{1} \mathrm{H}, \mathrm{B}\right){ }^{13} \mathrm{C}\left\{{ }^{1} \mathrm{H}\right\}$ and $\left.\mathrm{C}\right){ }^{11} \mathrm{~B}\left\{{ }^{1} \mathrm{H}\right\}$ NMR Spectra of 4BTe

2. X-Ray Crystallographic Data for BTe

3. X-Ray Crystallographic Data for B-Te-6-H

4. X-Ray Crystallographic Data for 4BSe 
Figure S1. A) ${ }^{1} \mathrm{H}$ NMR Spectrum of $2 \mathrm{BTe}$ in $\mathrm{CDCl}_{3}$
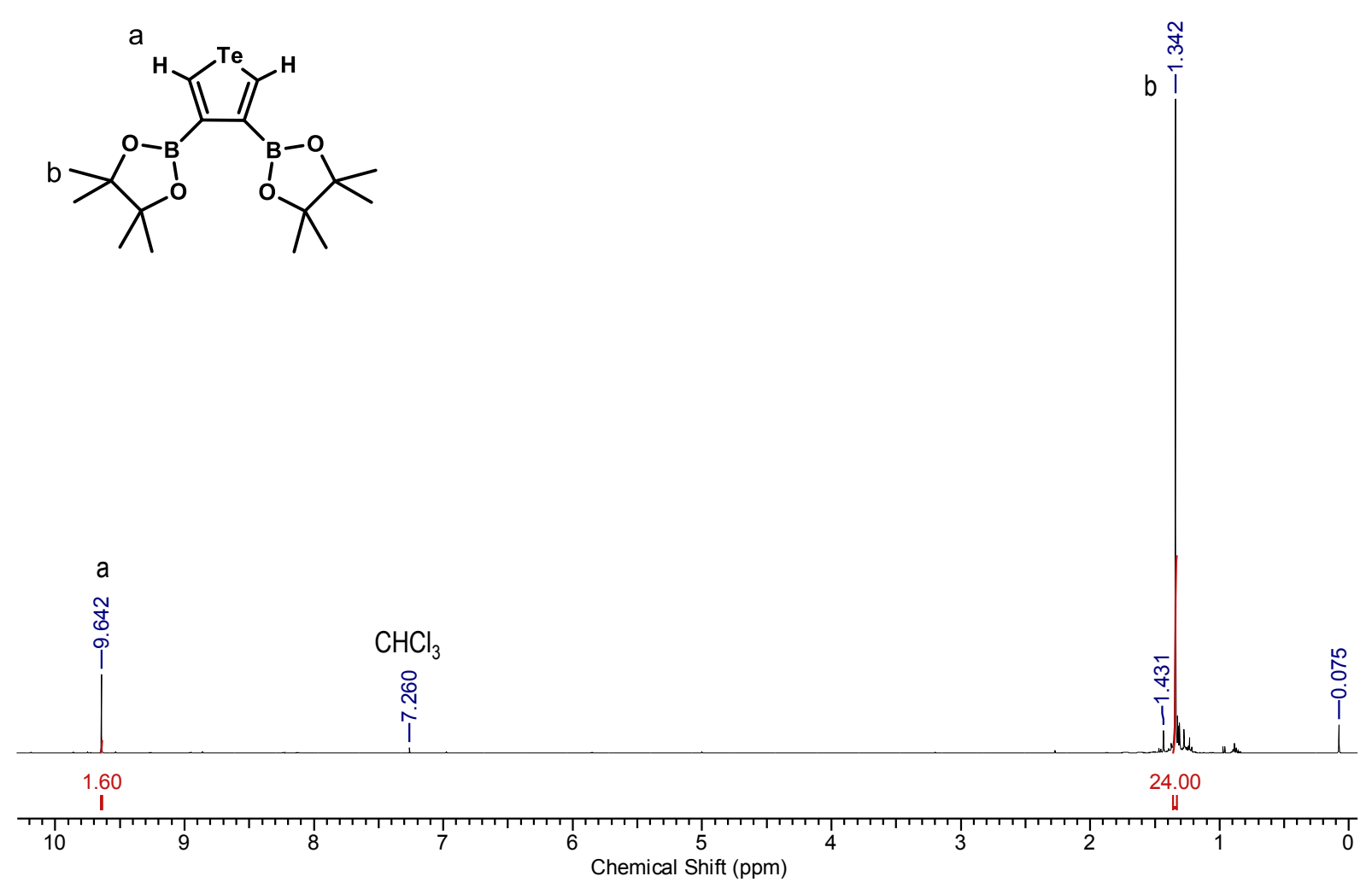

Figure S1. B) ${ }^{13} \mathrm{C}\left\{{ }^{1} \mathrm{H}\right\} \mathrm{NMR}$ Spectrum of $\mathbf{2 B T e}$ in $\mathrm{CDCl}_{3}$

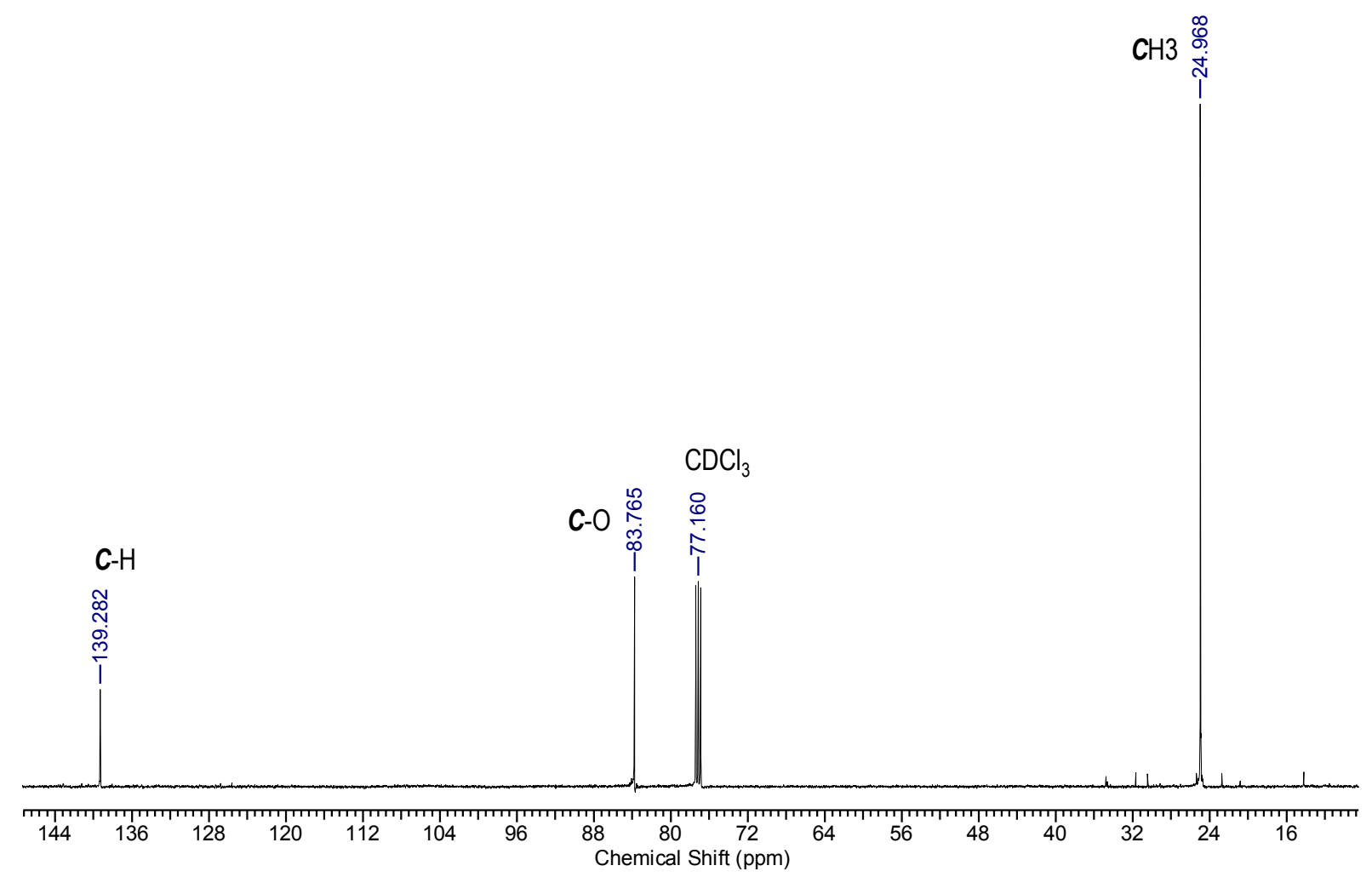


Figure S1. C) ${ }^{11} \mathrm{~B}\left\{{ }^{1} \mathrm{H}\right\}$ NMR Spectrum of $2 \mathrm{BTe}$ in $\mathrm{CDCl}_{3}$

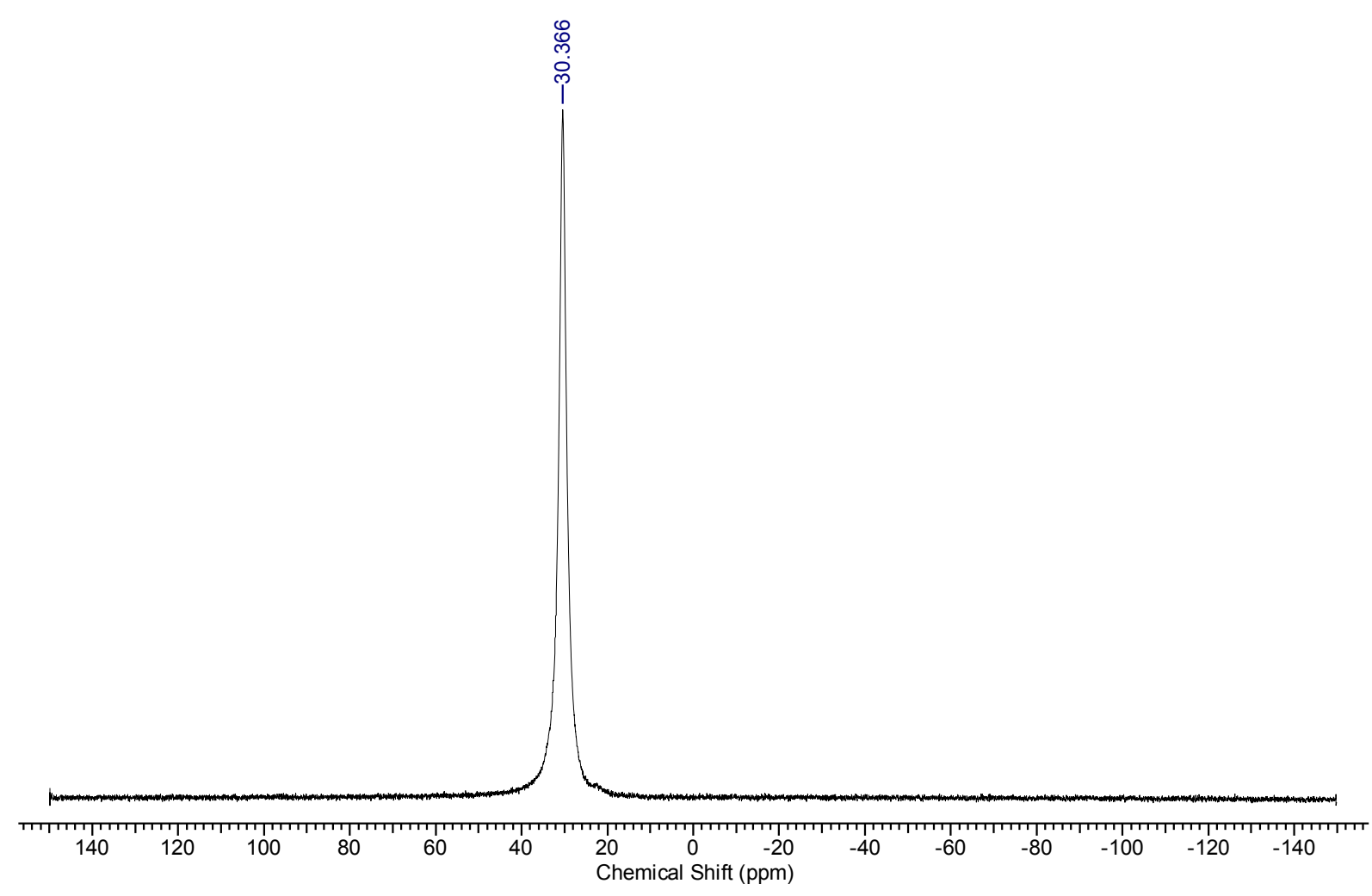


Figure S2. A) ${ }^{1} \mathrm{H}$ NMR Spectrum of BTe in $\mathrm{CDCl}_{3}$

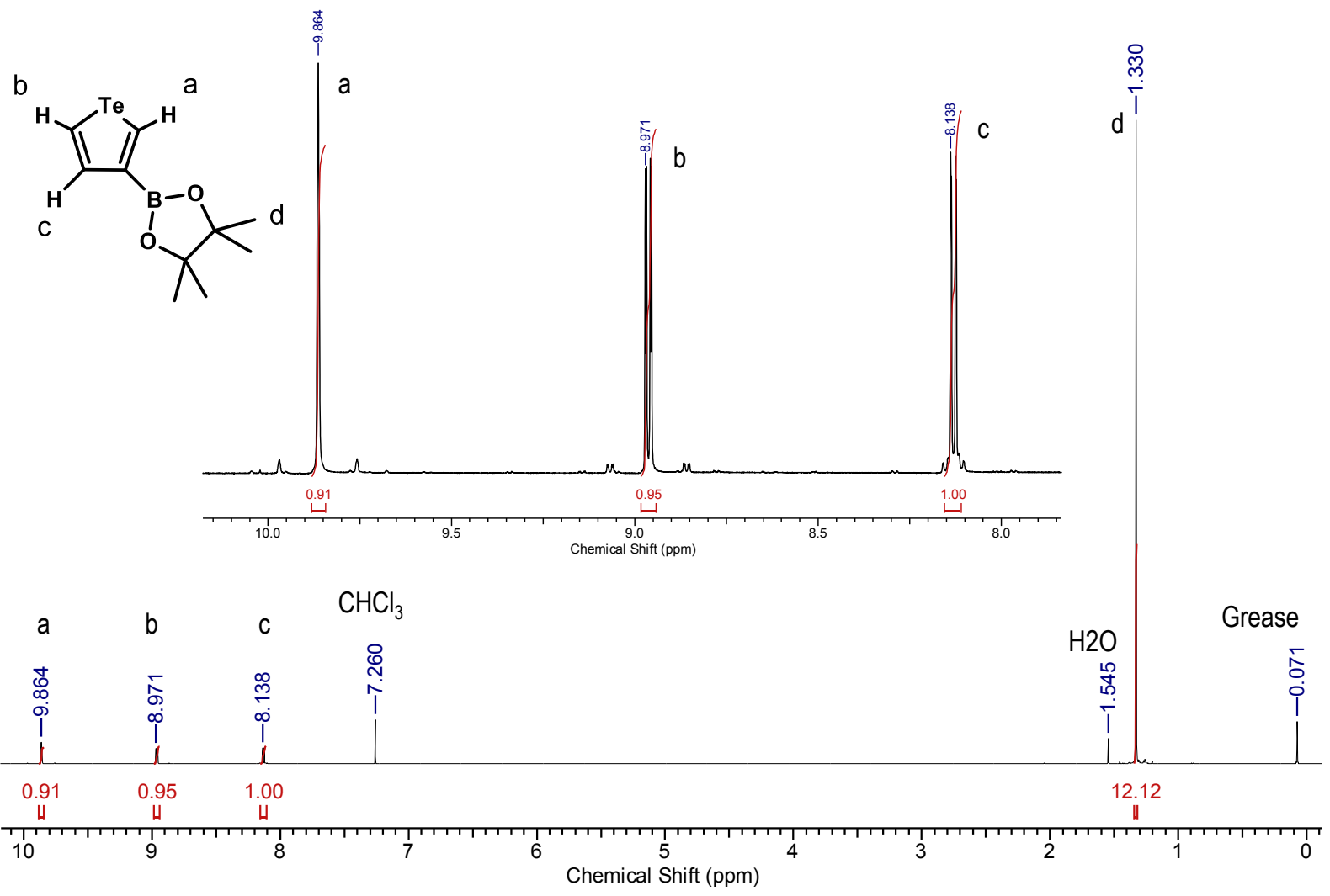

Figure S2. B) ${ }^{13} \mathrm{C}\left\{{ }^{1} \mathrm{H}\right\}$ NMR Spectrum of BTe in $\mathrm{CDCl}_{3}$

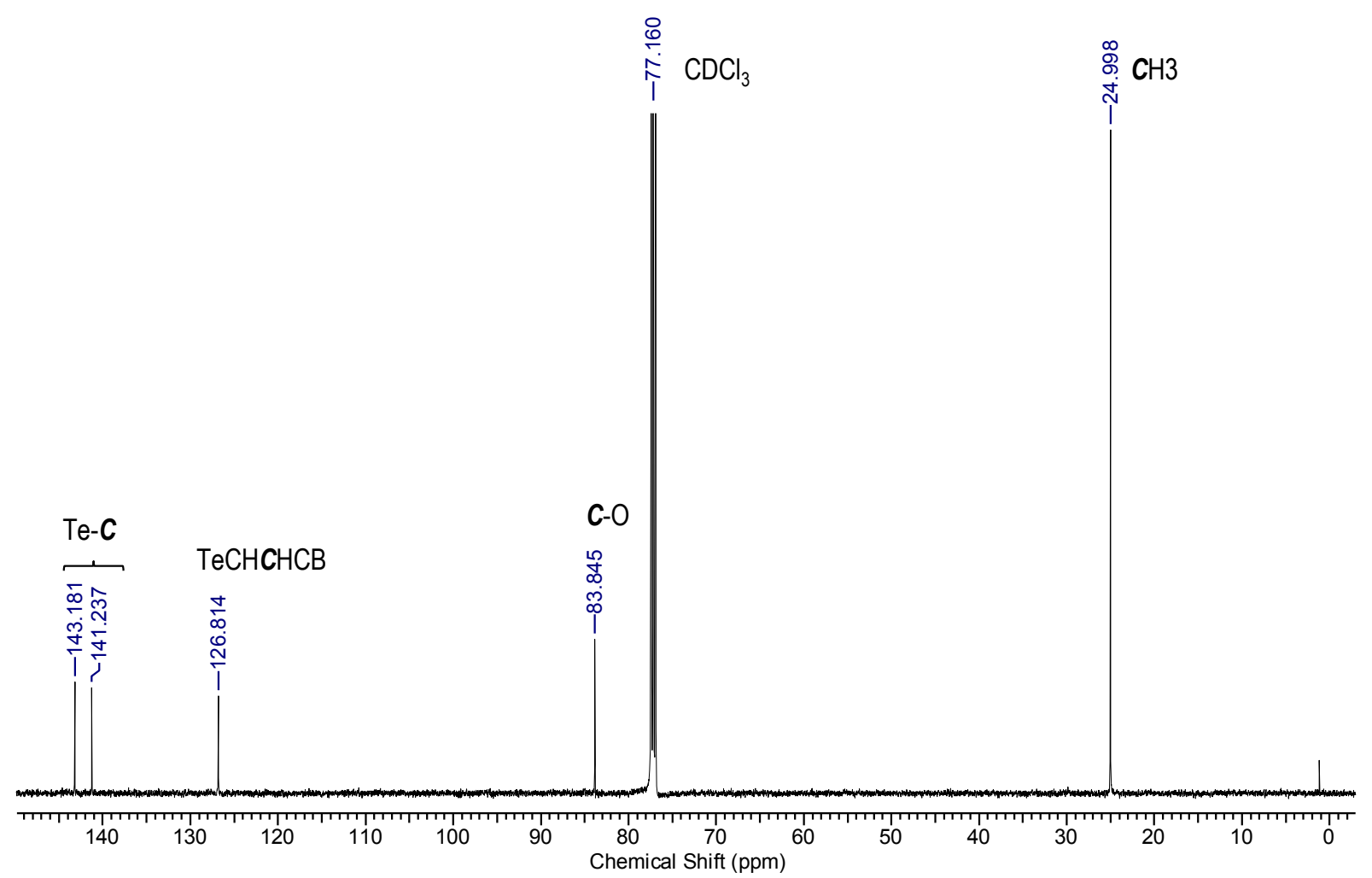


Figure S2. C) ${ }^{11} \mathrm{~B}\left\{{ }^{1} \mathrm{H}\right\}$ NMR Spectrum of BTe in $\mathrm{CDCl}_{3}$

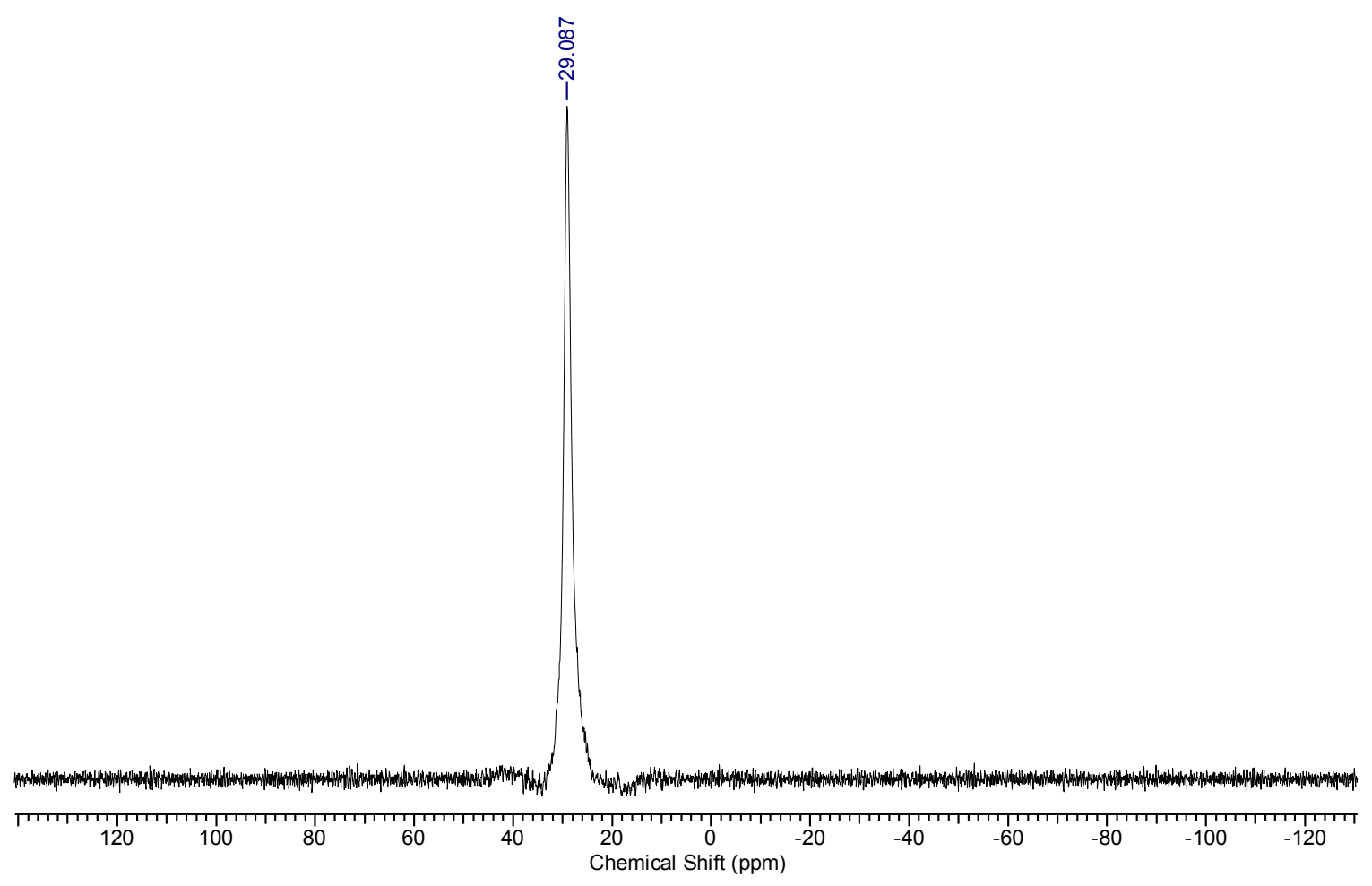


Figure S3. A) ${ }^{1} \mathrm{H}$ NMR Spectrum of B-Te-6-H in $\mathrm{CDCl}_{3}$<smiles></smiles>
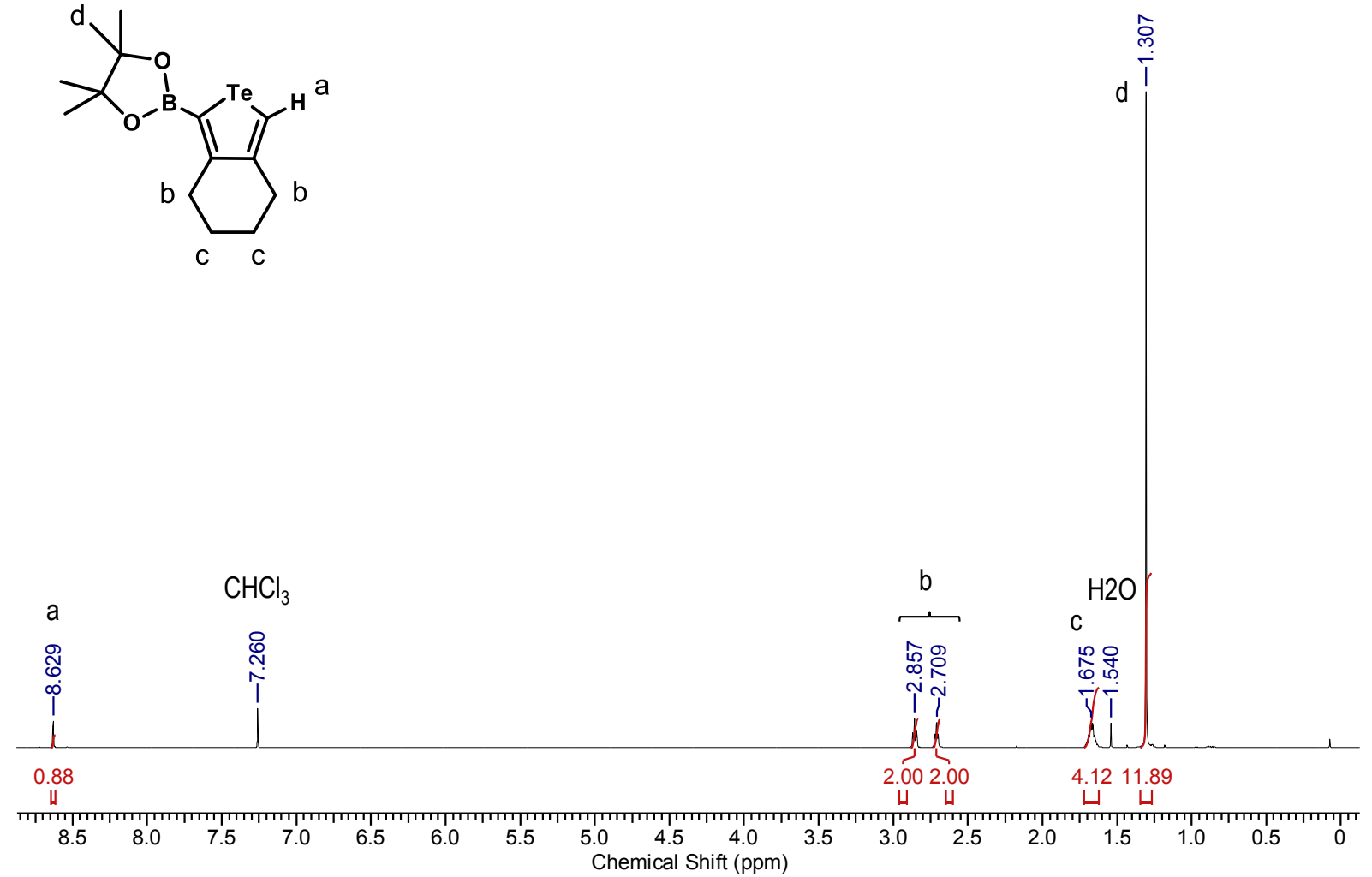

Figure S3. B) ${ }^{13} \mathrm{C}\left\{{ }^{1} \mathrm{H}\right\}$ NMR Spectrum of B-Te-6-H in $\mathrm{CDCl}_{3}$

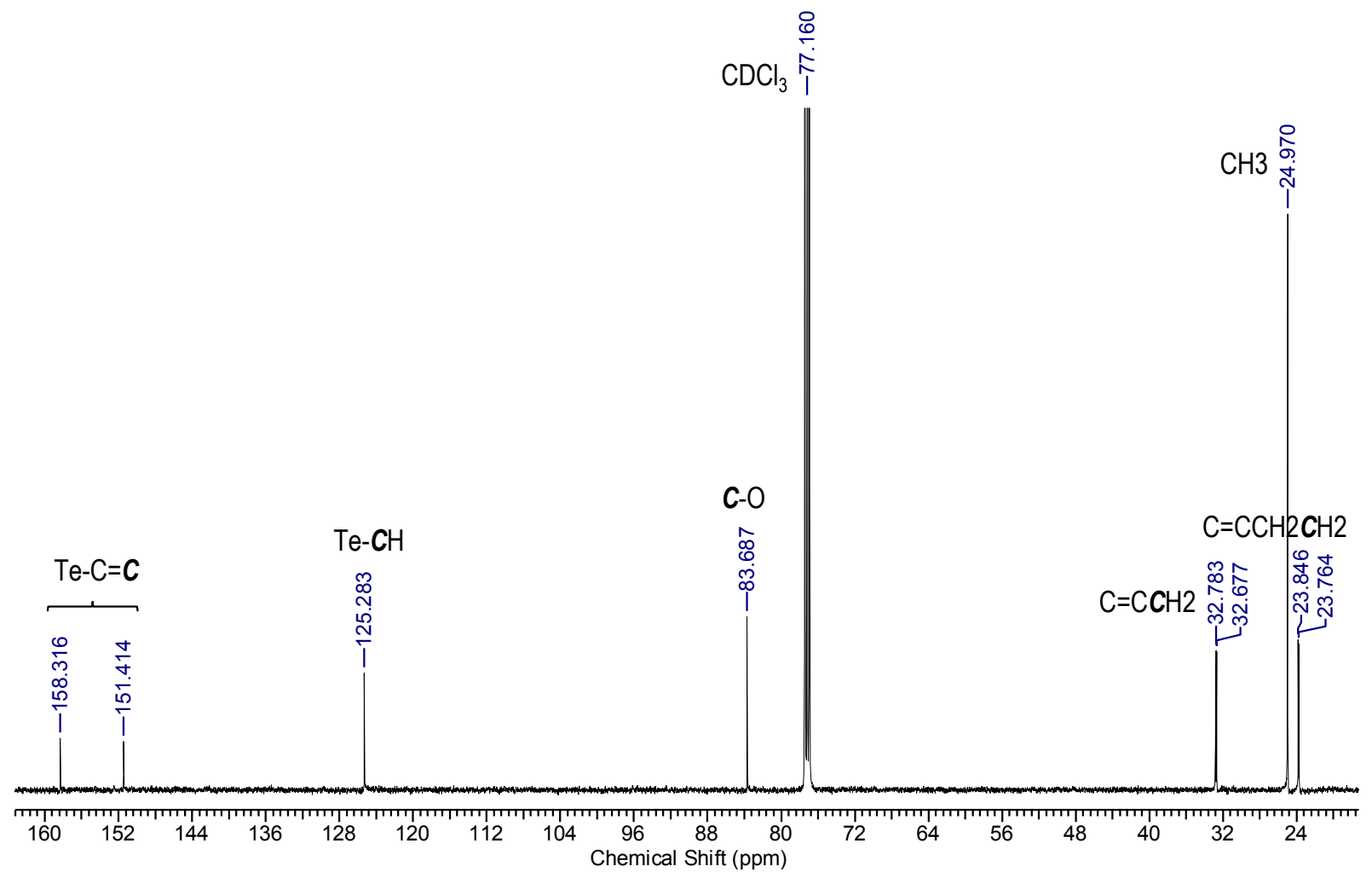


Figure S3. C) ${ }^{11} \mathrm{~B}\left\{{ }^{1} \mathrm{H}\right\}$ NMR Spectrum of B-Te-6-H in $\mathrm{CDCl}_{3}$

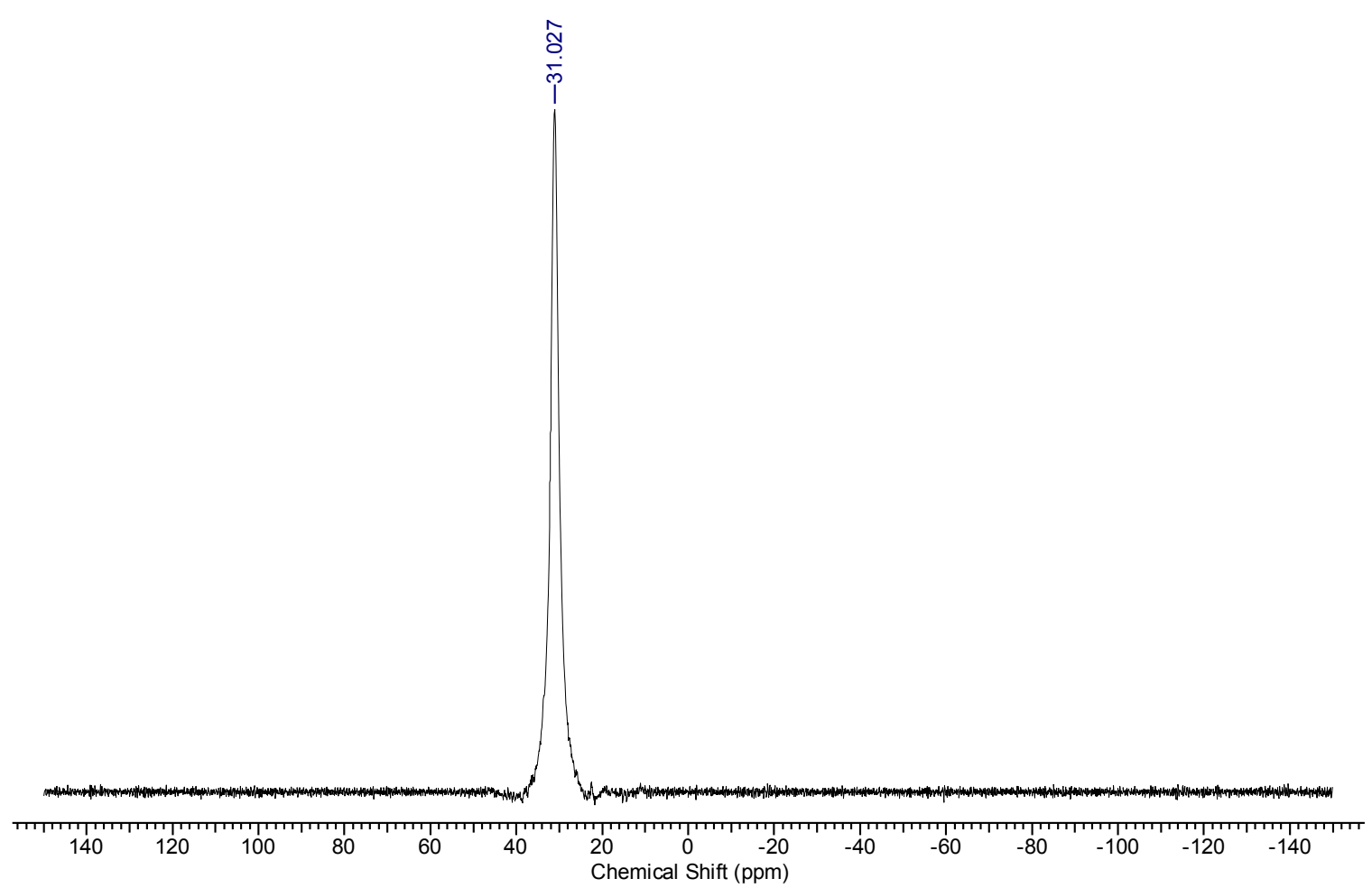


Figure S4. A) ${ }^{1} \mathrm{H}$ NMR Spectrum of $\mathbf{H}-\mathbf{T e}-\mathbf{6}-\mathbf{H}$ in $\mathrm{CDCl}_{3}$

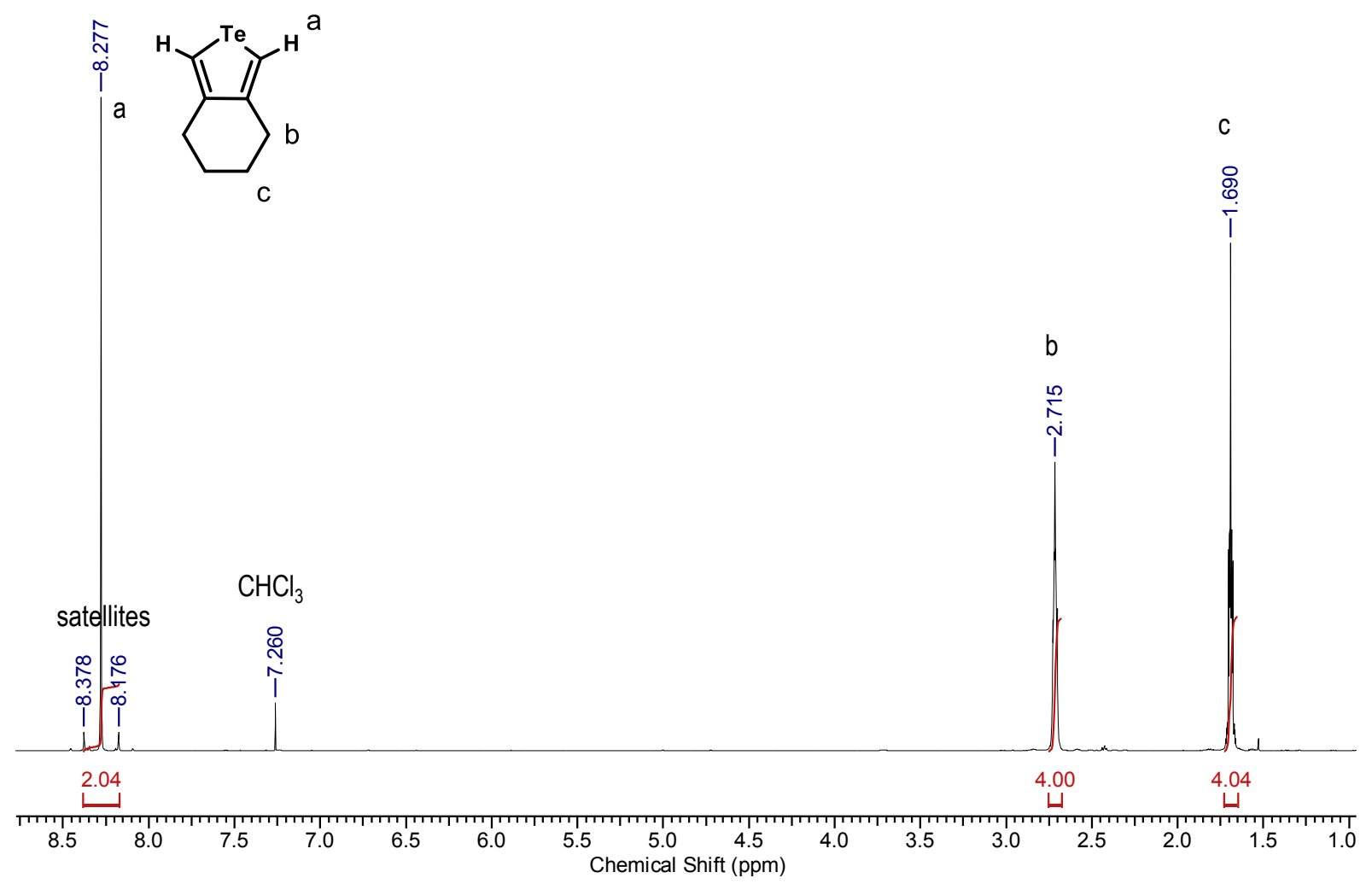

Figure S4. B) ${ }^{13} \mathrm{C}\left\{{ }^{1} \mathrm{H}\right\}$ NMR Spectrum of $\mathbf{H}-\mathbf{T e}-\mathbf{6}-\mathbf{H}$ in $\mathrm{CDCl}_{3}$

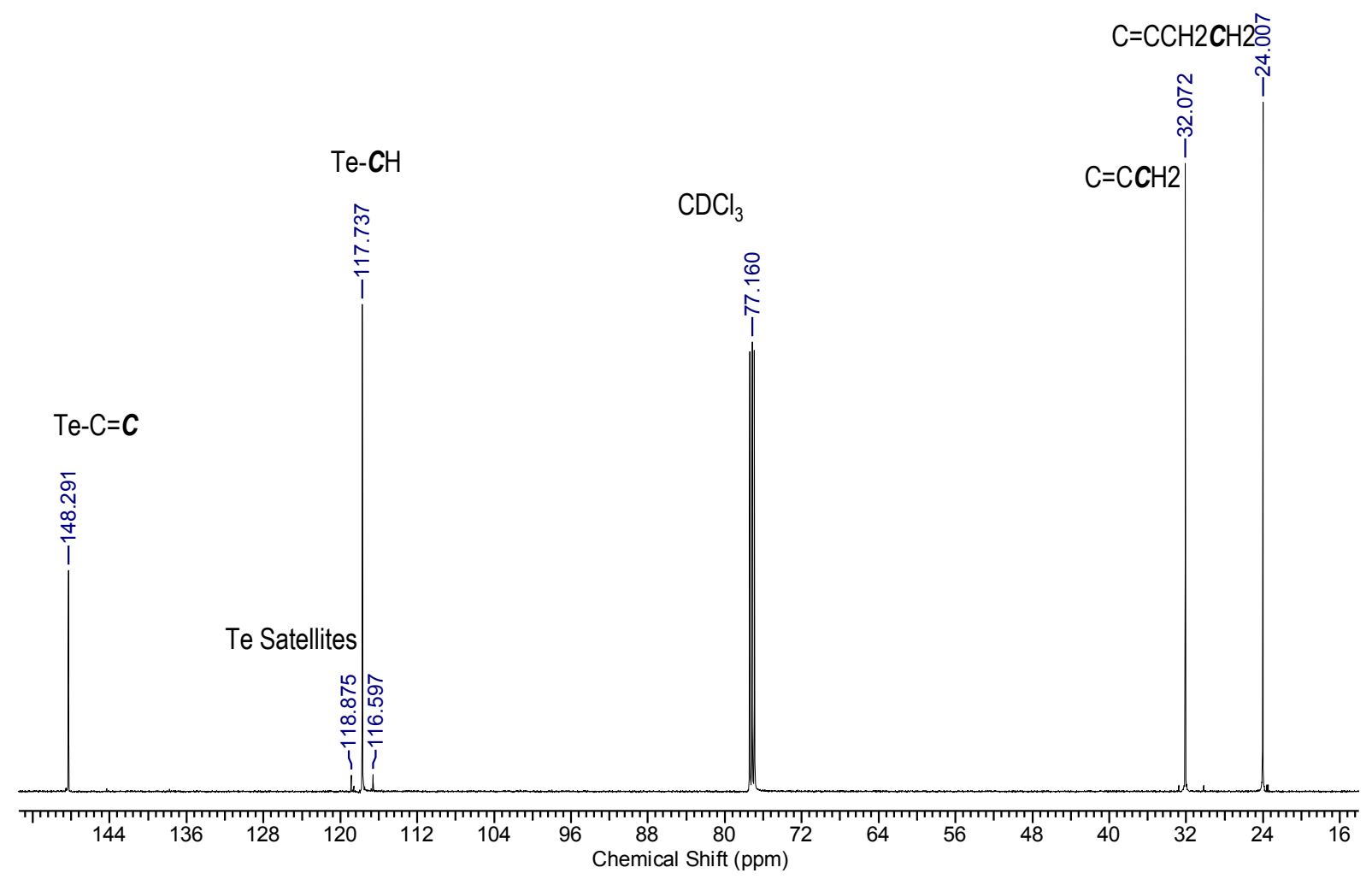


Figure S5. A) ${ }^{1} \mathrm{H}$ NMR Spectrum of $\mathrm{Br}-\mathrm{Te}-6-\mathrm{Br}$ in $\mathrm{CDCl}_{3}$<smiles></smiles>

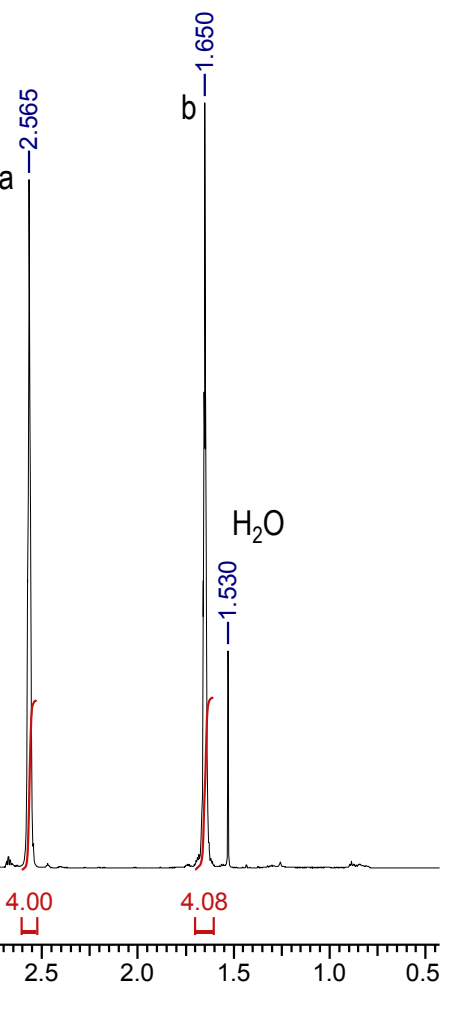

Figure S5. B) ${ }^{13} \mathrm{C}\left\{{ }^{1} \mathrm{H}\right\}$ NMR Spectrum of $\mathrm{Br}-\mathrm{Te}-6-\mathrm{Br}$ in $\mathrm{CDCl}_{3}$

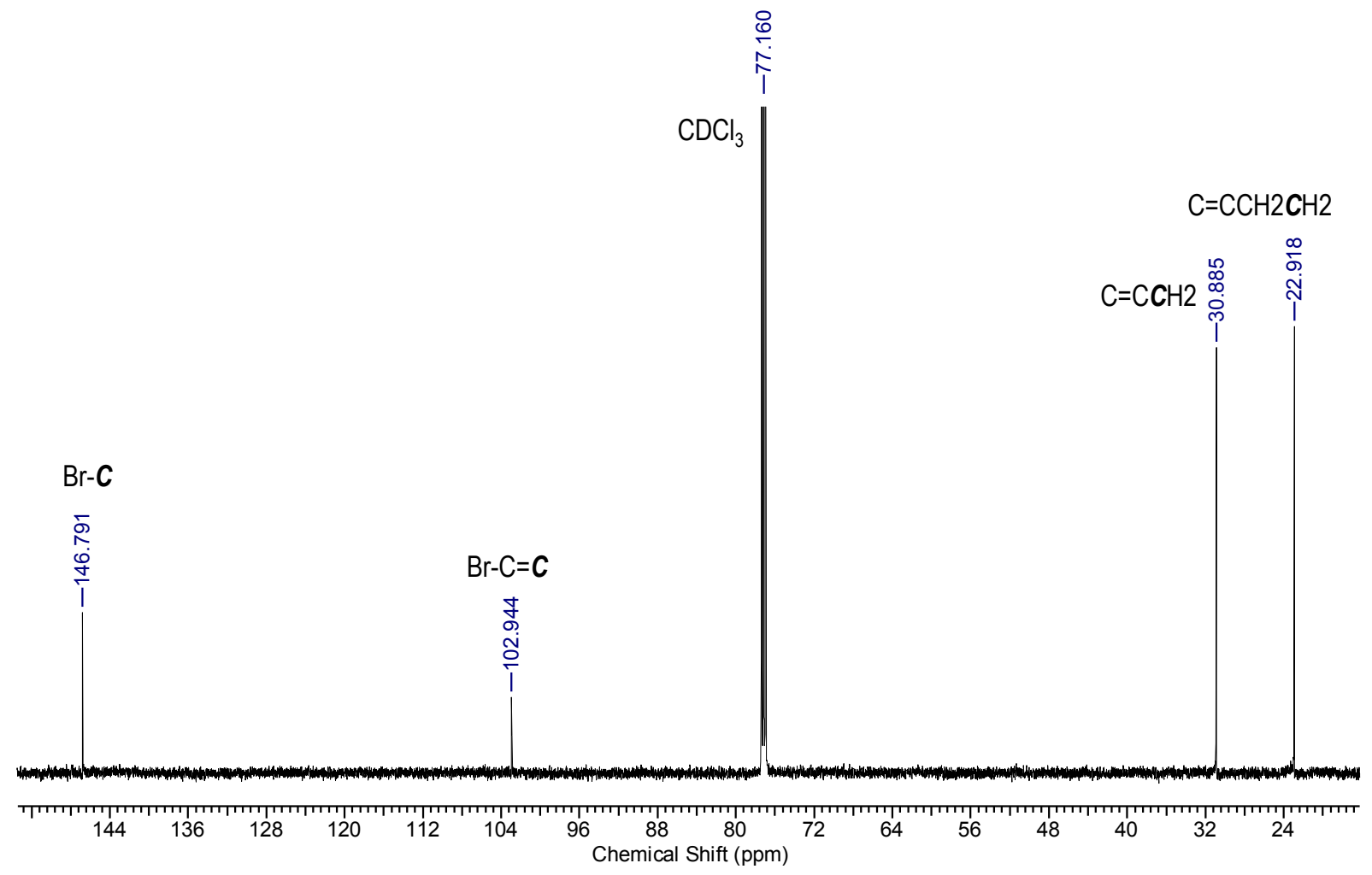


Figure S6. A) ${ }^{1} \mathrm{H}$ NMR Spectrum of $2 \mathrm{BrTe}$ in $\mathrm{CDCl}_{3}$

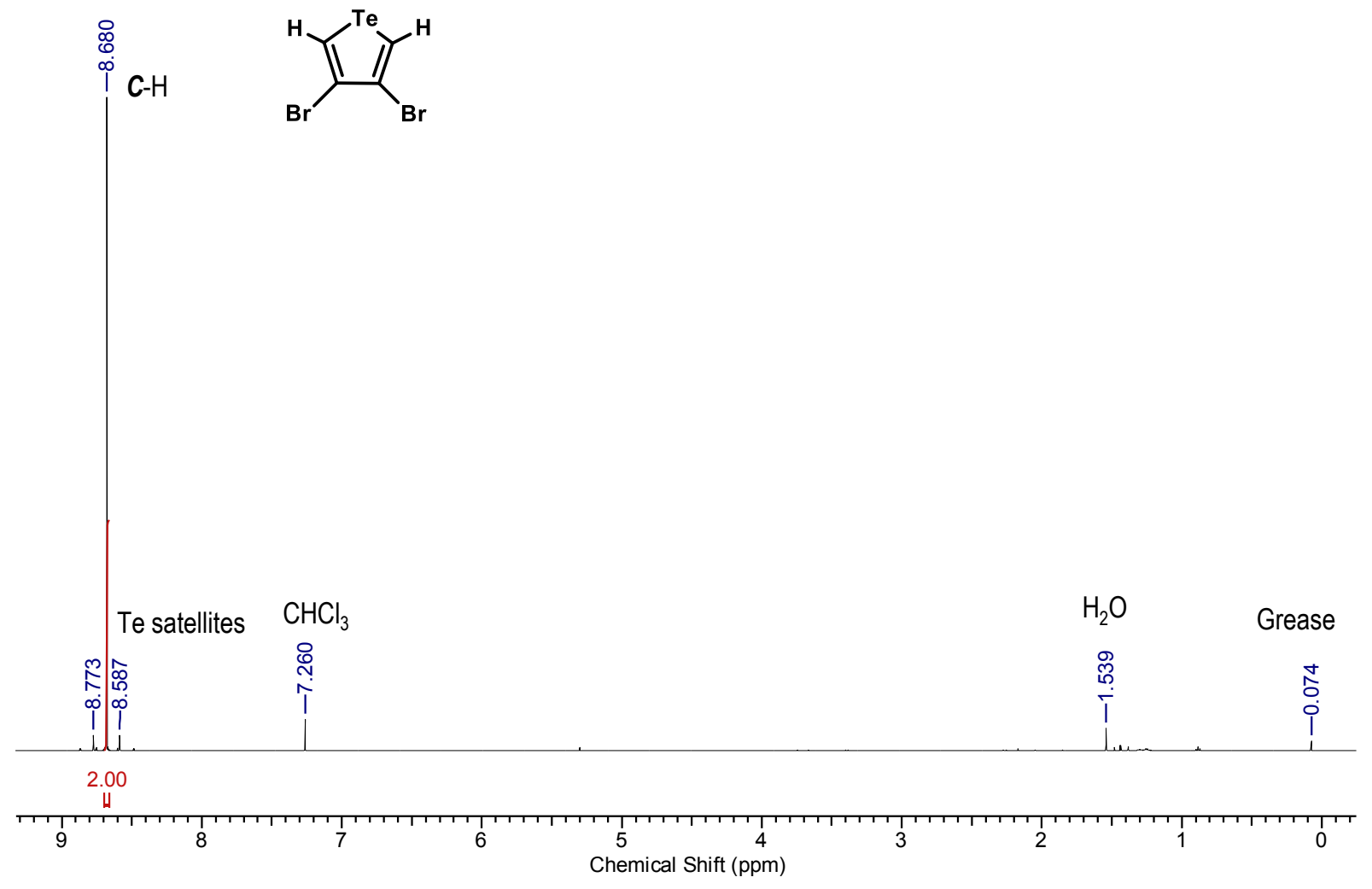

Figure S6. B) ${ }^{13} \mathrm{C}\left\{{ }^{1} \mathrm{H}\right\}$ NMR Spectrum of $2 \mathrm{BrTe}$ in $\mathrm{CDCl}_{3}$

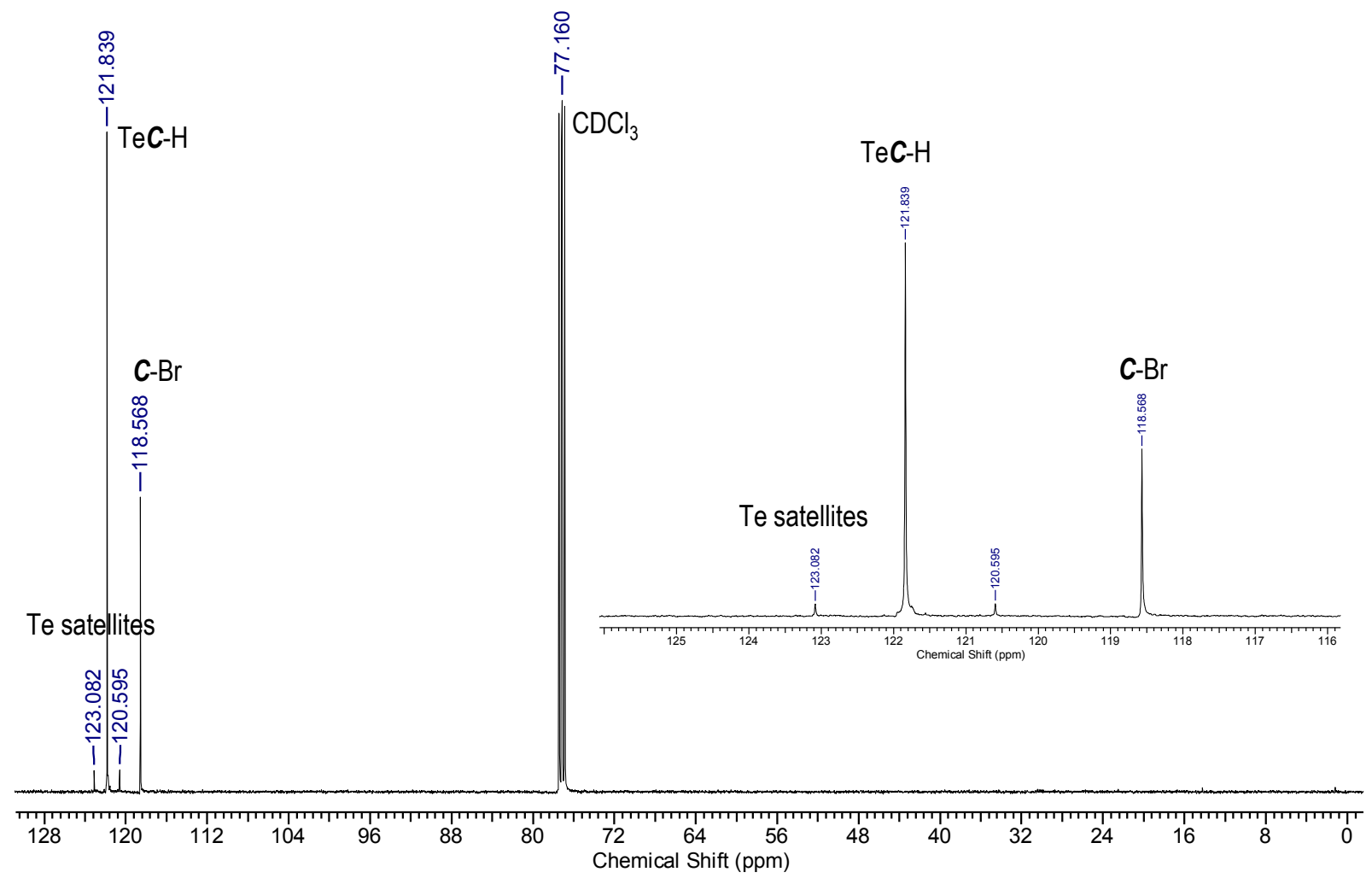


Figure S7. A) ${ }^{1} \mathrm{H}$ NMR Spectrum of BrTe in $\mathrm{CDCl}_{3}$

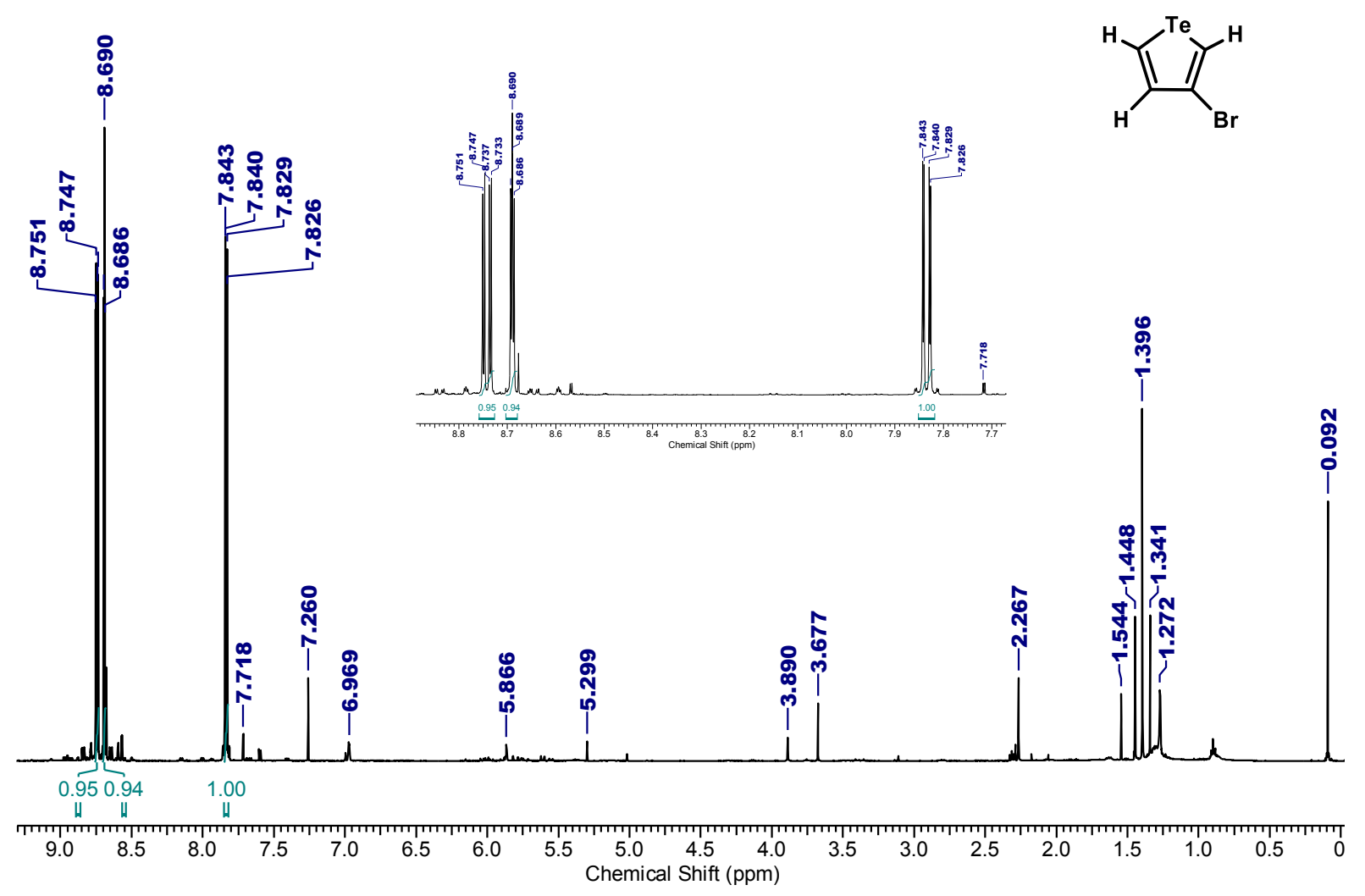

Figure S7. B) ${ }^{13} \mathrm{C}\left\{{ }^{1} \mathrm{H}\right\}$ NMR Spectrum of BrTe in $\mathrm{CDCl}_{3}$

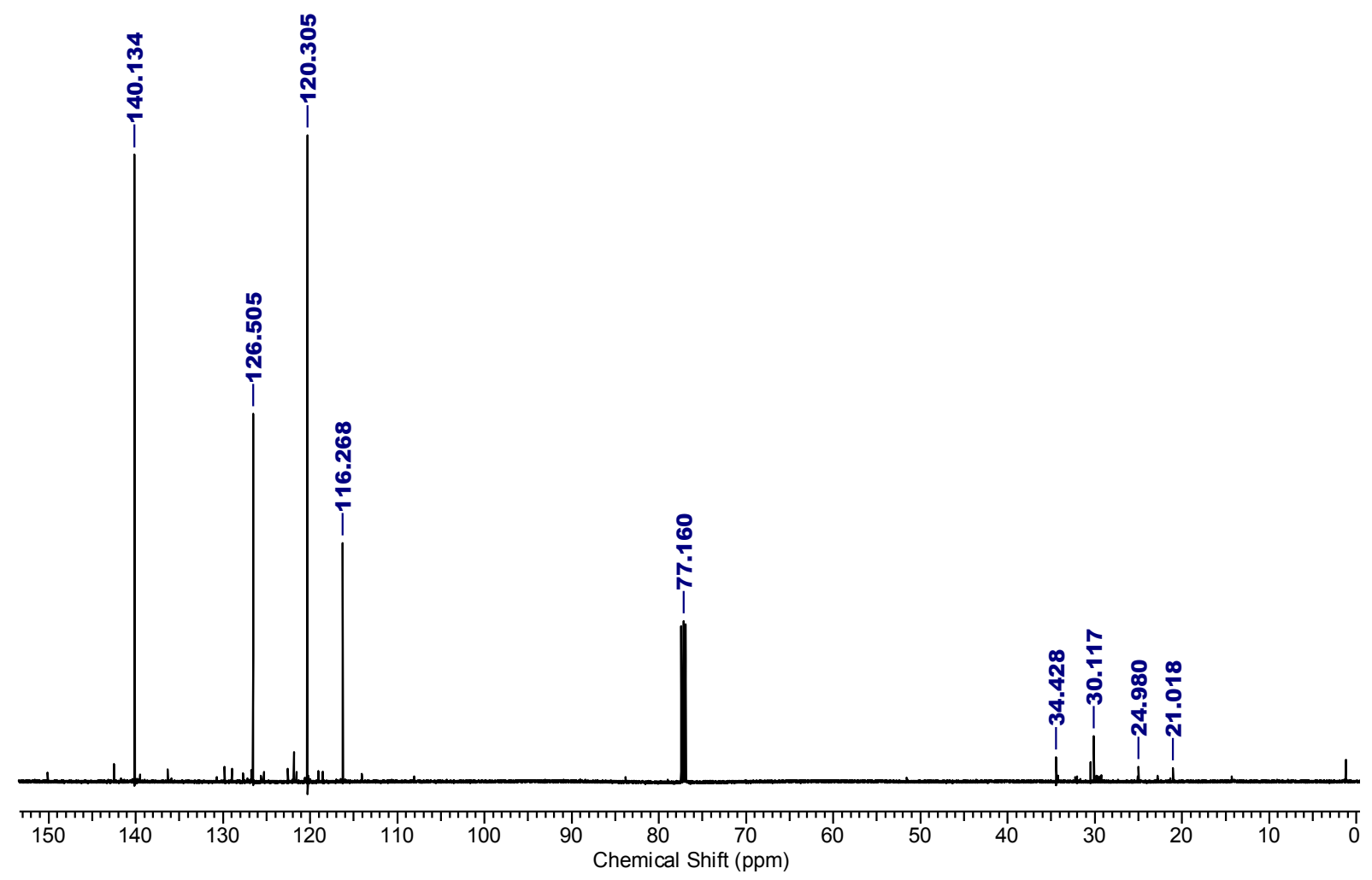


Figure S8. A) ${ }^{1} \mathrm{H}$ NMR Spectrum of $\mathbf{B}-\mathrm{TeBr}_{2}-6-\mathbf{B}$ in $\mathrm{CDCl}_{3}$
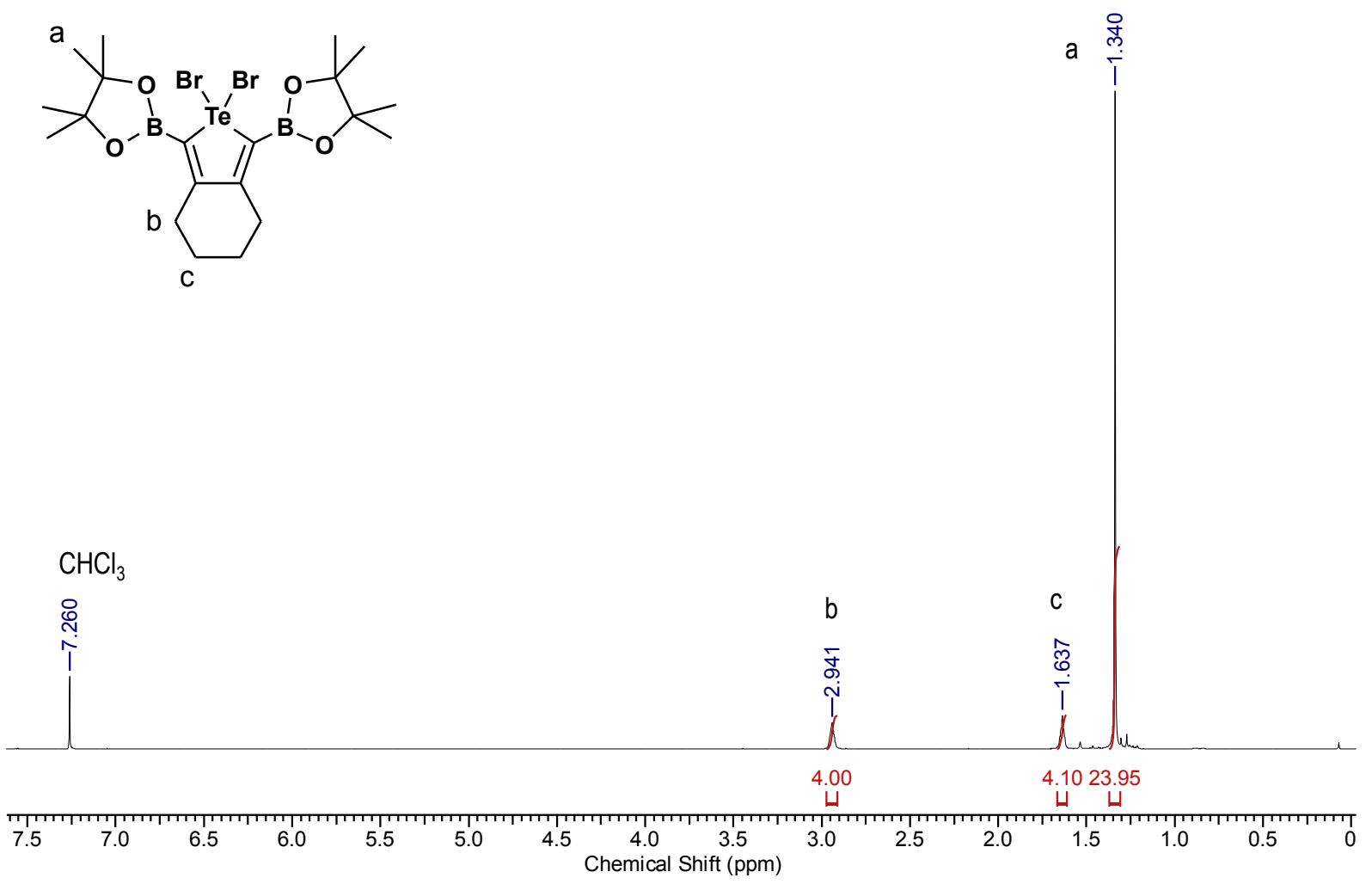

Figure S8. B) ${ }^{13} C\left\{{ }^{1} \mathrm{H}\right\}$ NMR Spectrum of $\mathbf{B}-\mathrm{TeBr}_{2}-\mathbf{6}-\mathbf{B}$ in $\mathrm{CDCl}_{3}$

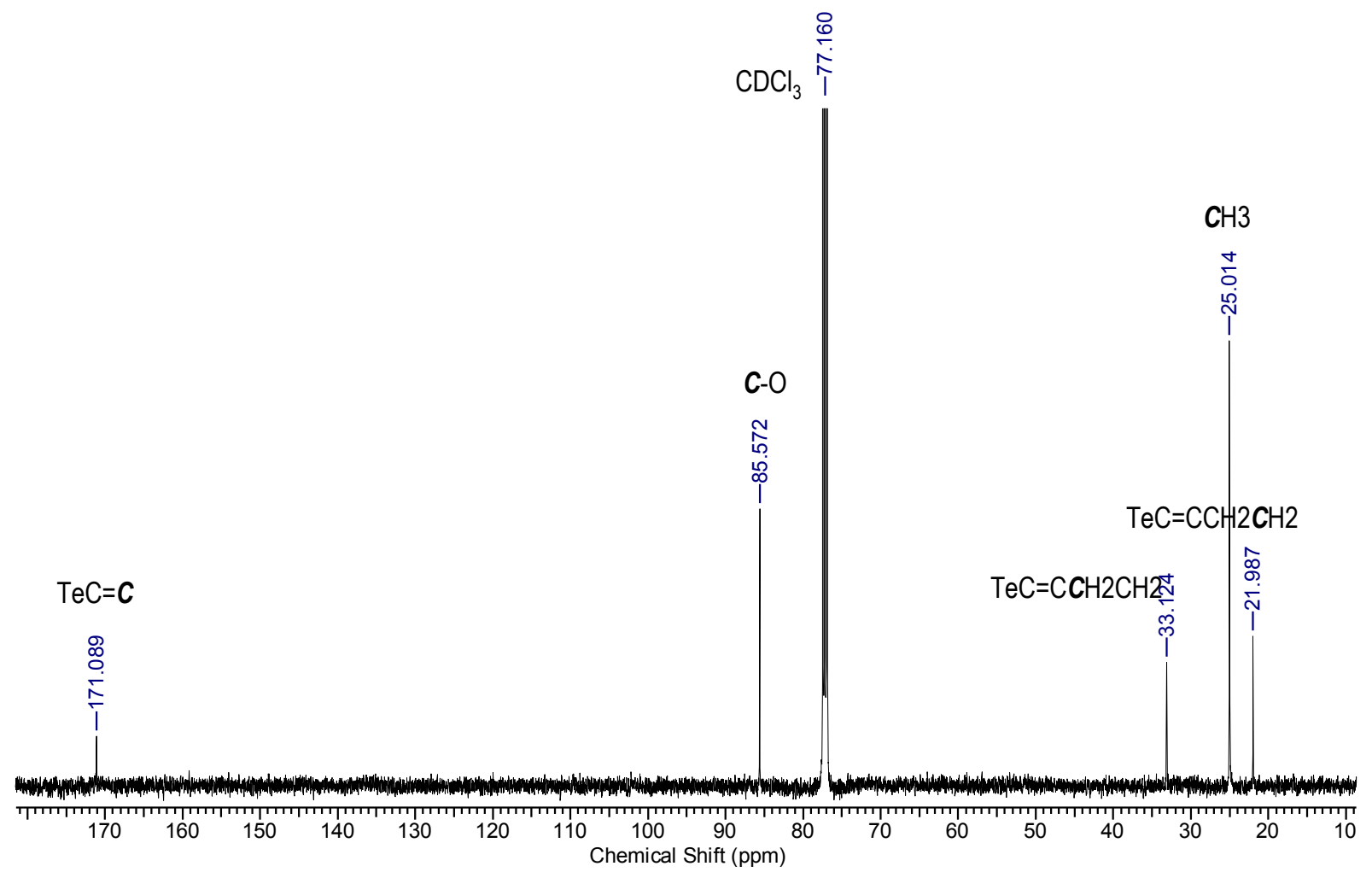


Figure S8. C) ${ }^{11} \mathrm{~B}\left\{{ }^{1} \mathrm{H}\right\}$ NMR Spectrum of $\mathbf{B}-\mathrm{TeBr}_{2}-\mathbf{6}-\mathbf{B}$ in $\mathrm{CDCl}_{3}$

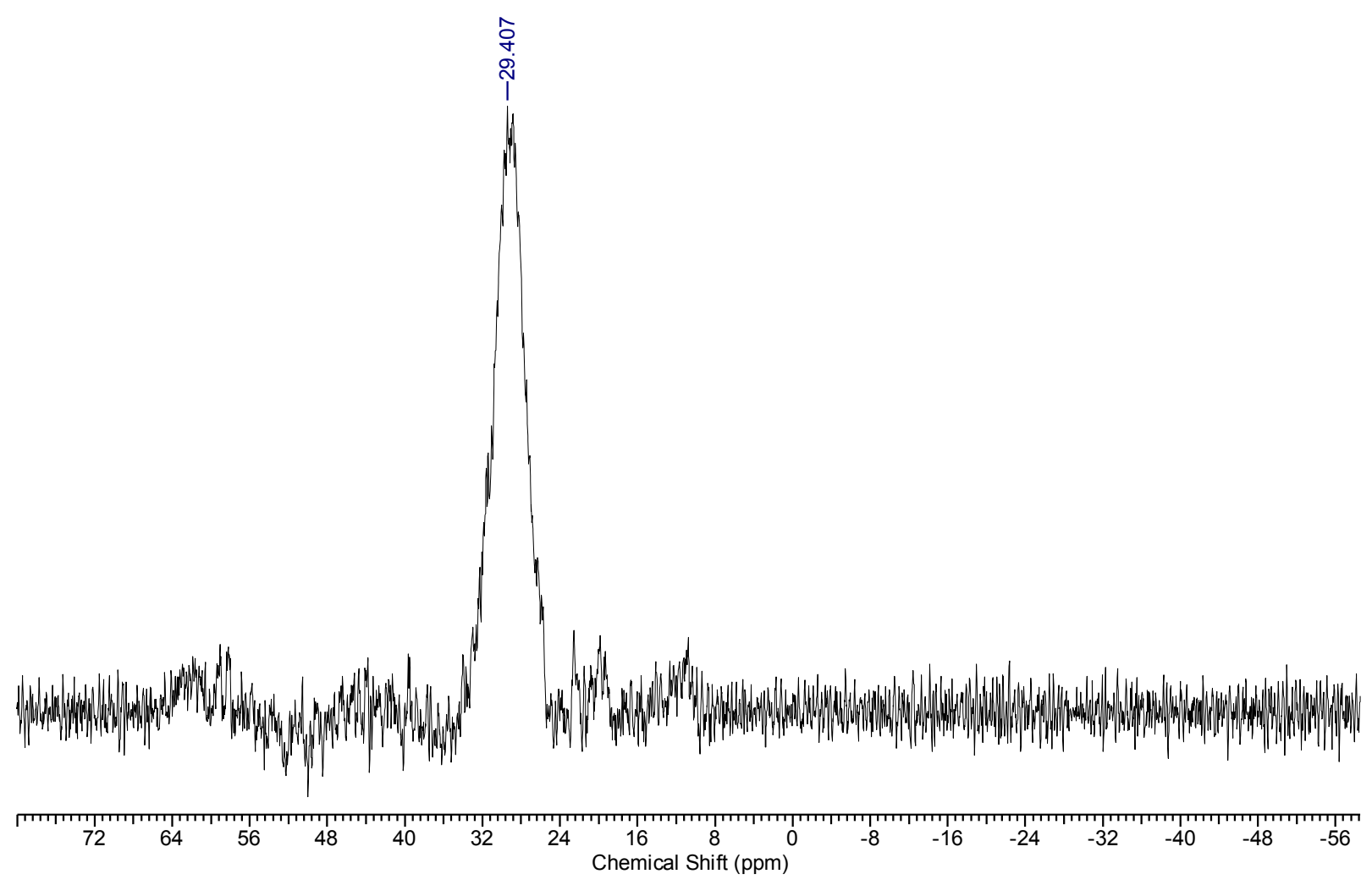


Figure S9. A) ${ }^{1} \mathrm{H}$ NMR Spectrum of $4 \mathrm{BS}$ in $\mathrm{CDCl}_{3}$<smiles>CC1(C)OB(c2sc(B3OC(C)(C)C(C)(C)O3)c(B3OC(C)(C)C(C)(C)O3)c2B2OC(C)(C)C(C)(C)O2)OC1(C)C</smiles>

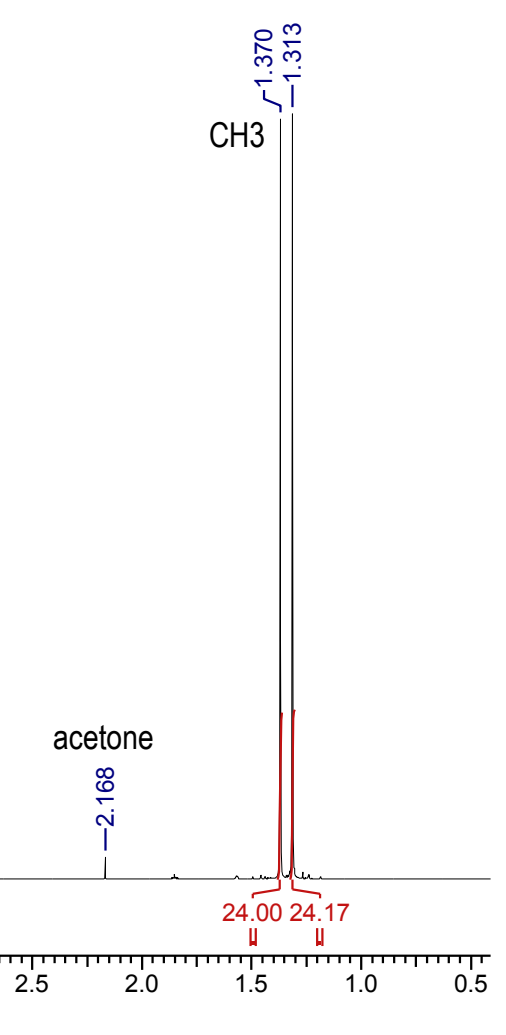

Figure S9. B) ${ }^{13} \mathrm{C}\left\{{ }^{1} \mathrm{H}\right\}$ NMR Spectrum of 4BS in $\mathrm{CDCl}_{3}$

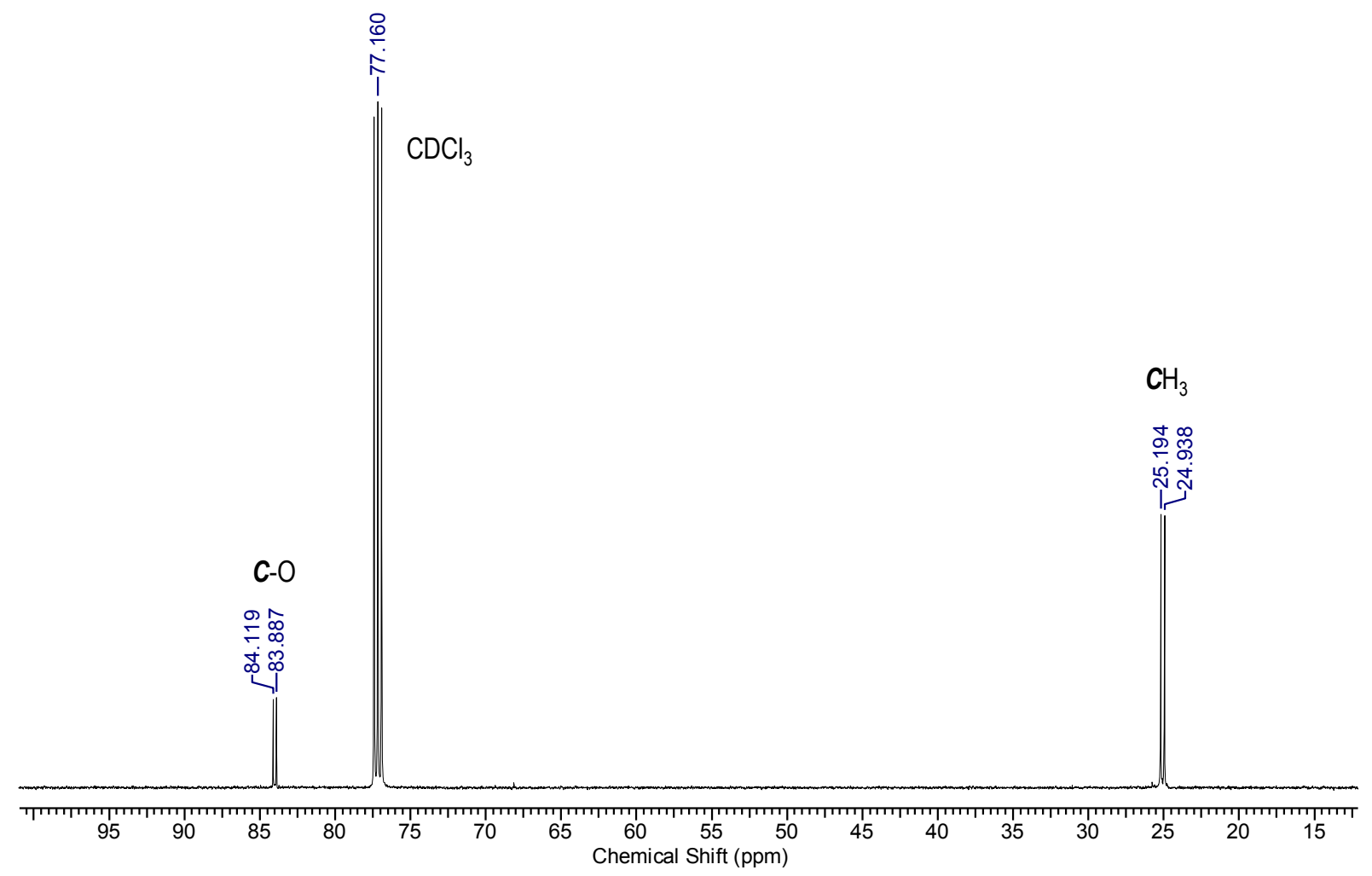


Figure S9. C) ${ }^{11} B\left\{{ }^{1} \mathrm{H}\right\}$ NMR Spectrum of 4BS in $\mathrm{CDCl}_{3}$

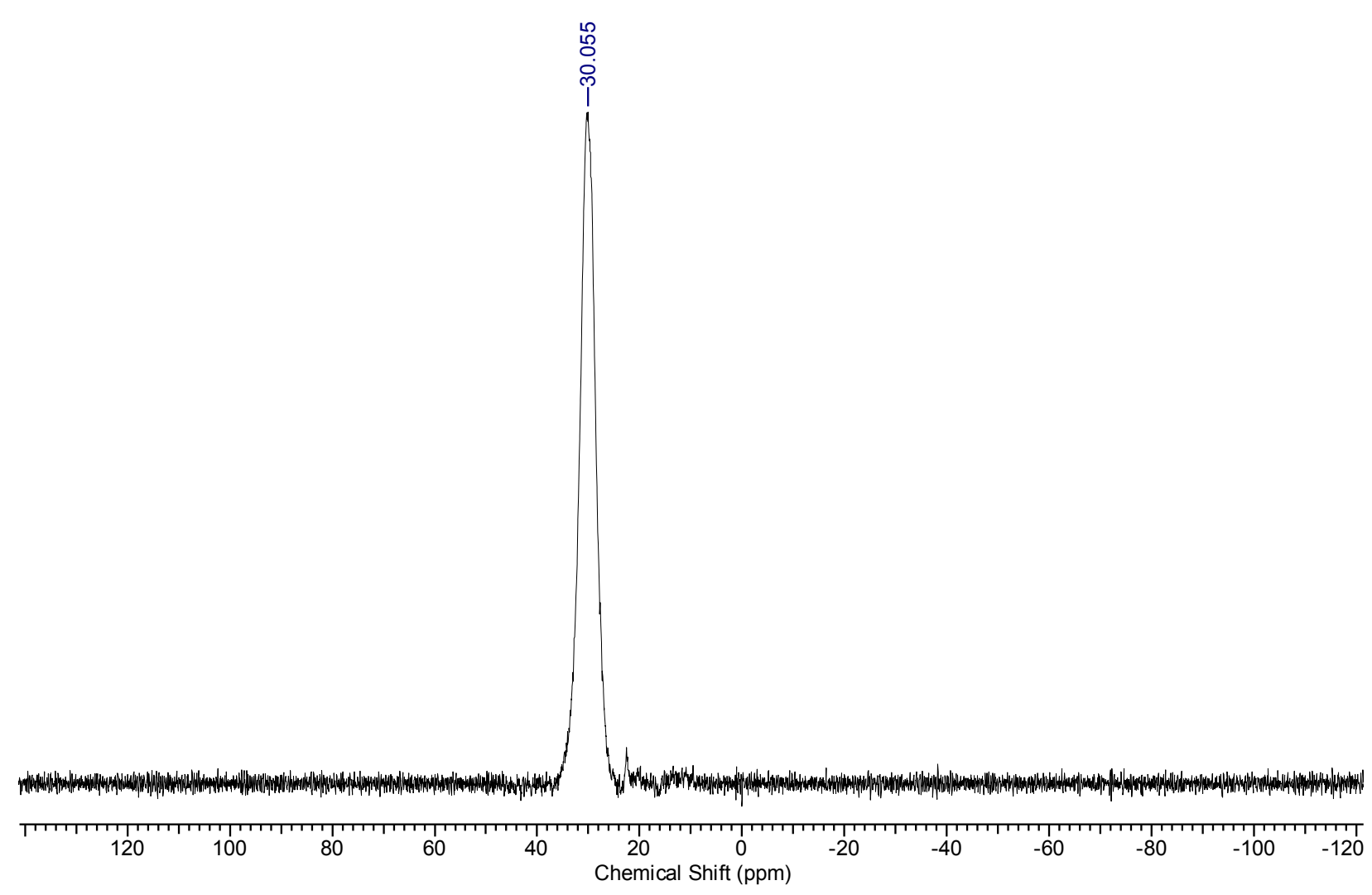


Figure S10. A) ${ }^{1} \mathrm{H}-\mathrm{NMR}$ Spectrum of a Mixture of BS and 2BS in $\mathrm{CDCl}_{3}$

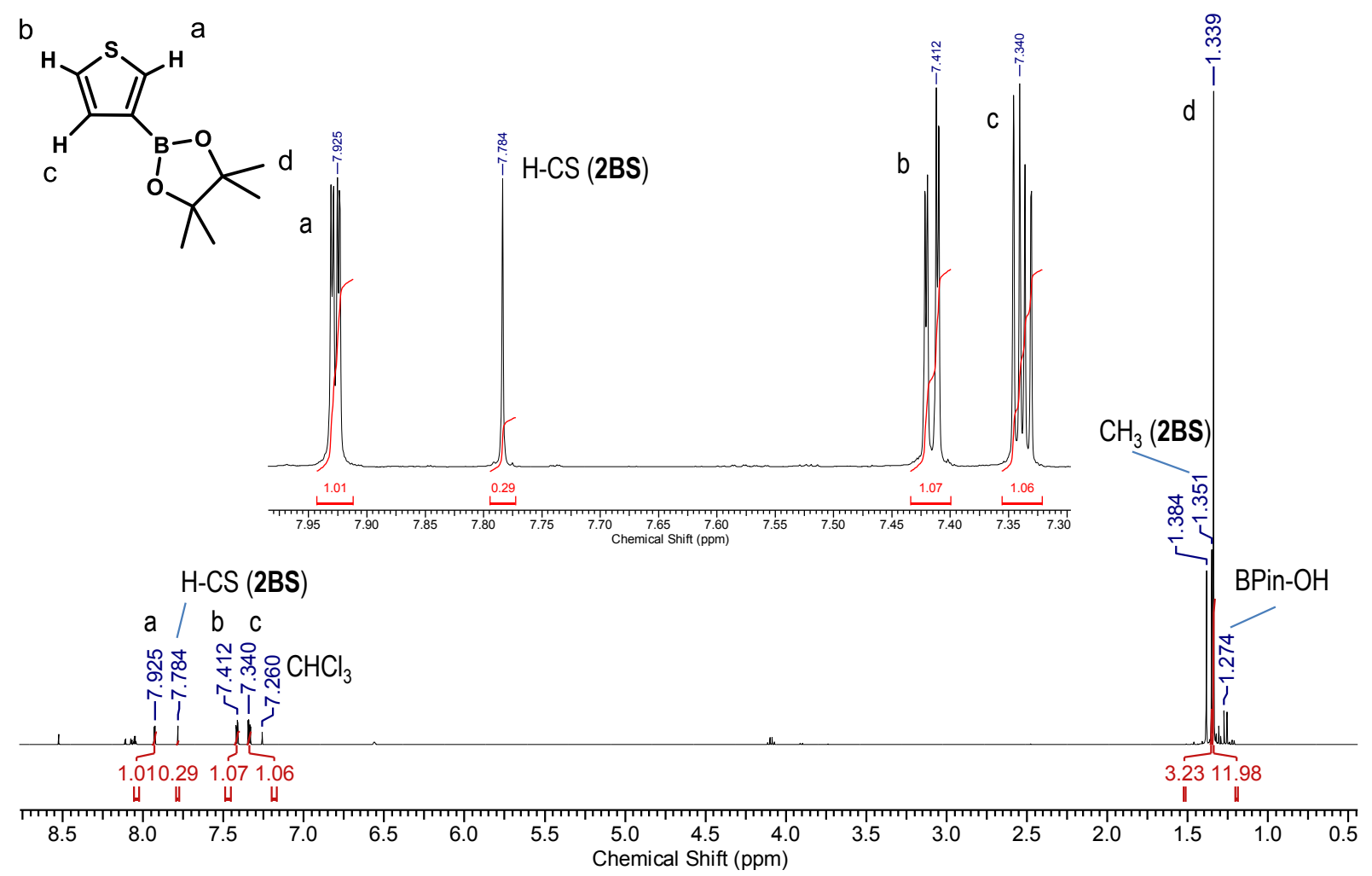

Figure S10. B) ${ }^{13} \mathrm{C}\left\{{ }^{1} \mathrm{H}\right\}$ NMR Spectrum of a Mixture of BS and 2BS in $\mathrm{CDCl}_{3}$

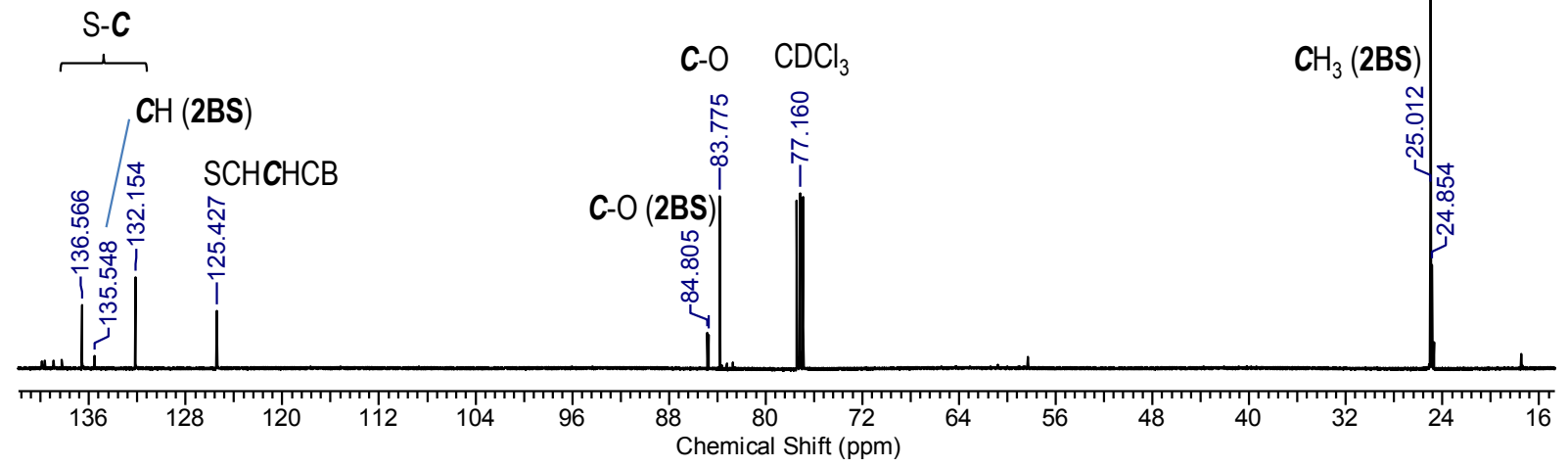


Figure S10. C) ${ }^{11} \mathrm{~B}\left\{{ }^{1} \mathrm{H}\right\}$ NMR Spectrum of a Mixture of $\mathbf{B S}$ and $\mathbf{2 B S}$ in $\mathrm{CDCl}_{3}$

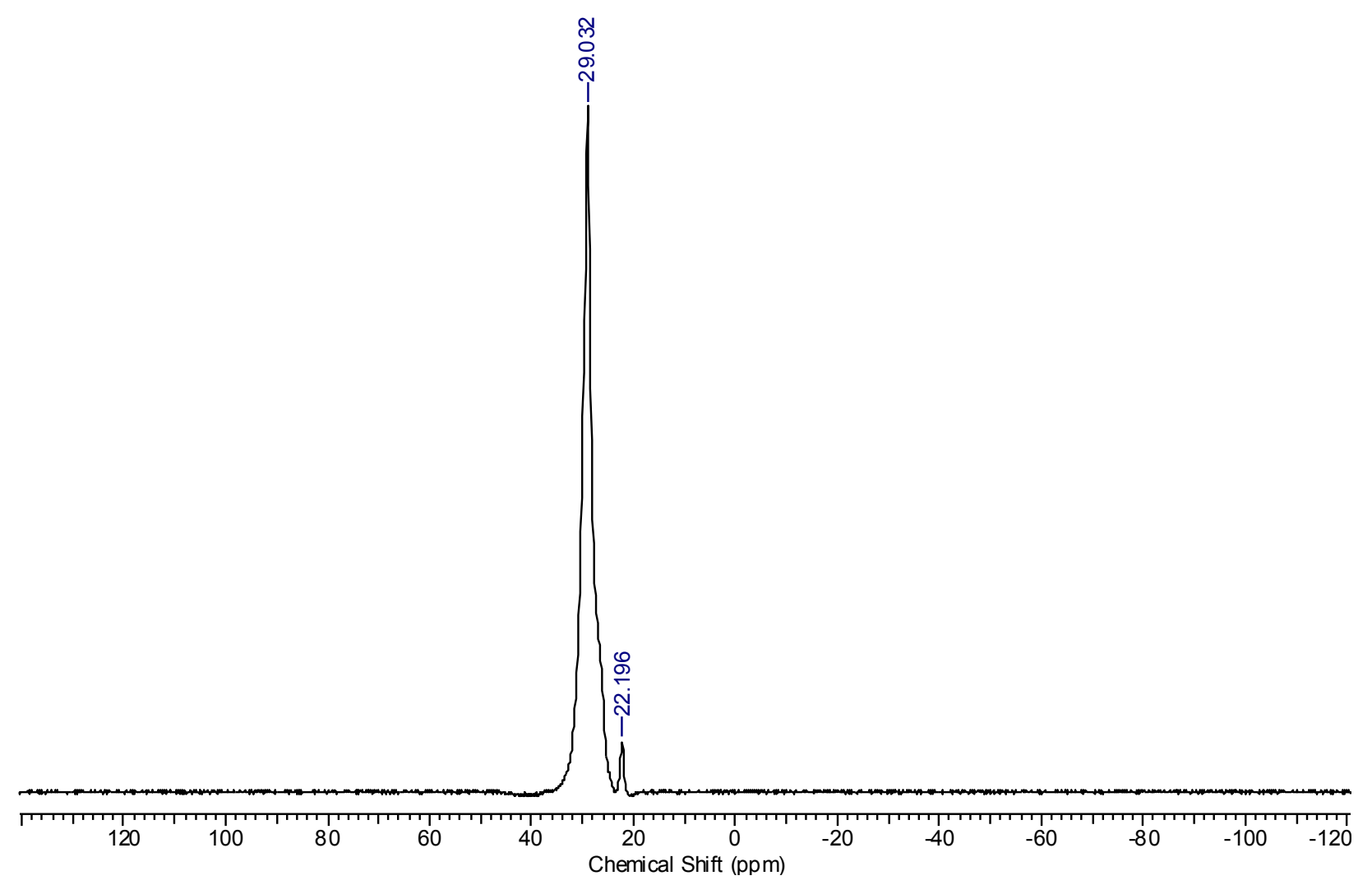


Figure S11. A) ${ }^{1} \mathrm{H}$ NMR Spectrum of 4BSe in $\mathrm{CDCl}_{3}$<smiles>CC1(C)OB(c2sc(B3OC(C)(C)C(C)(C)O3)c(B3OC(C)(C)C(C)(C)O3)c2B2OC(C)(C)C(C)(C)O2)OC1(C)C</smiles><smiles></smiles>

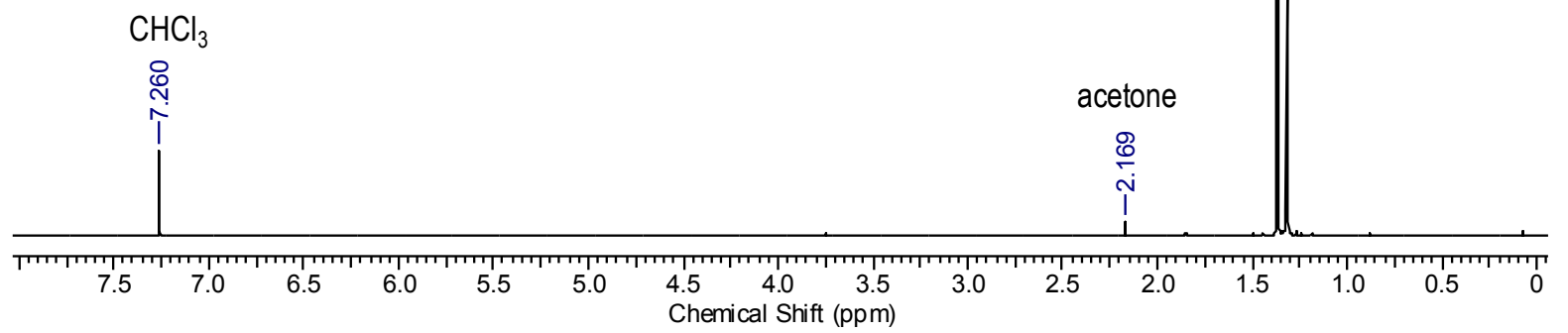

Figure S11. B) ${ }^{13} \mathrm{C}\left\{{ }^{1} \mathrm{H}\right\}$ NMR Spectrum of 4BSe in $\mathrm{CDCl}_{3}$

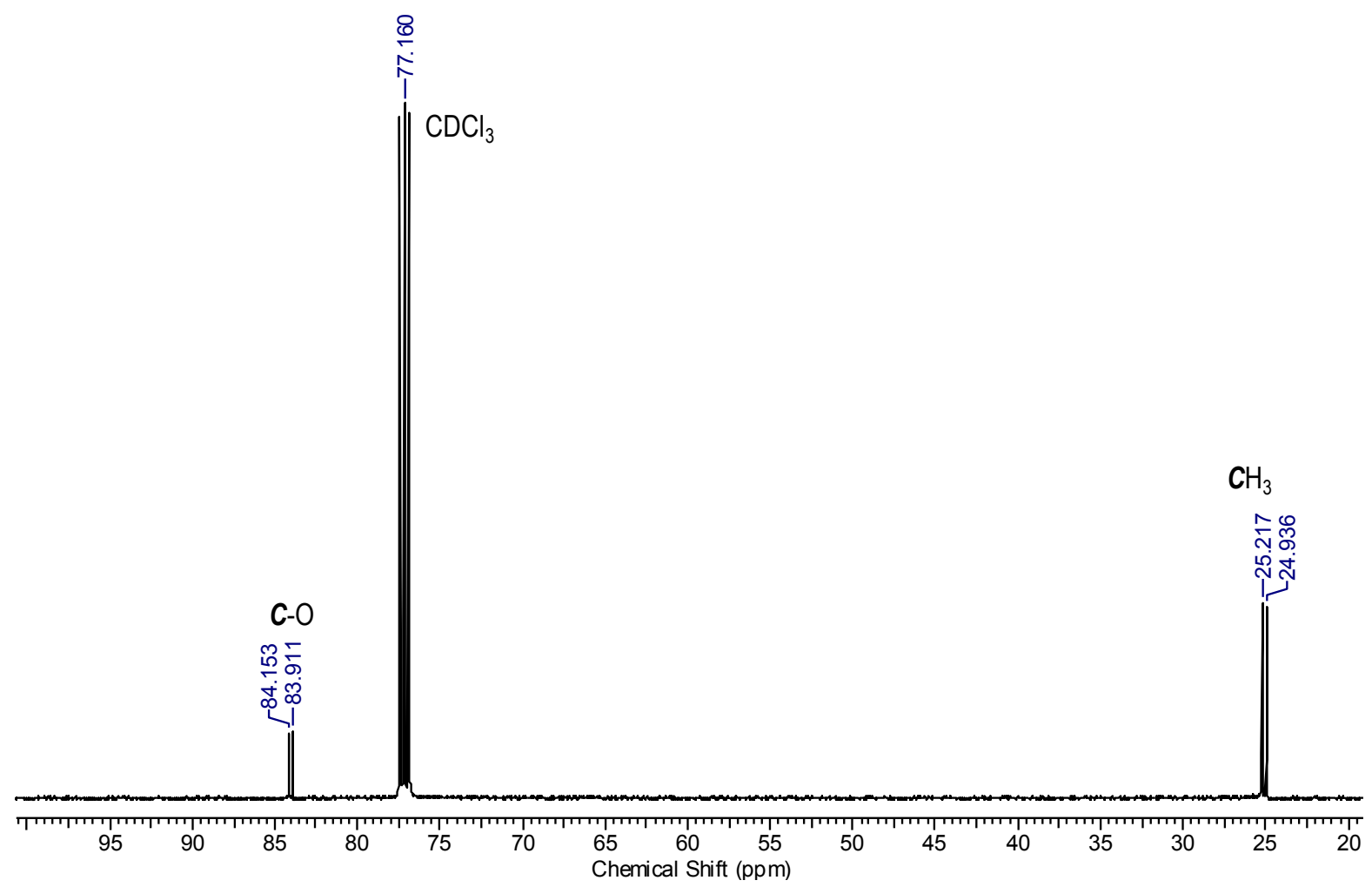


Figure S11. C) ${ }^{11} \mathrm{~B}\left\{{ }^{1} \mathrm{H}\right\}$ NMR Spectrum of 4BSe in $\mathrm{CDCl}_{3}$

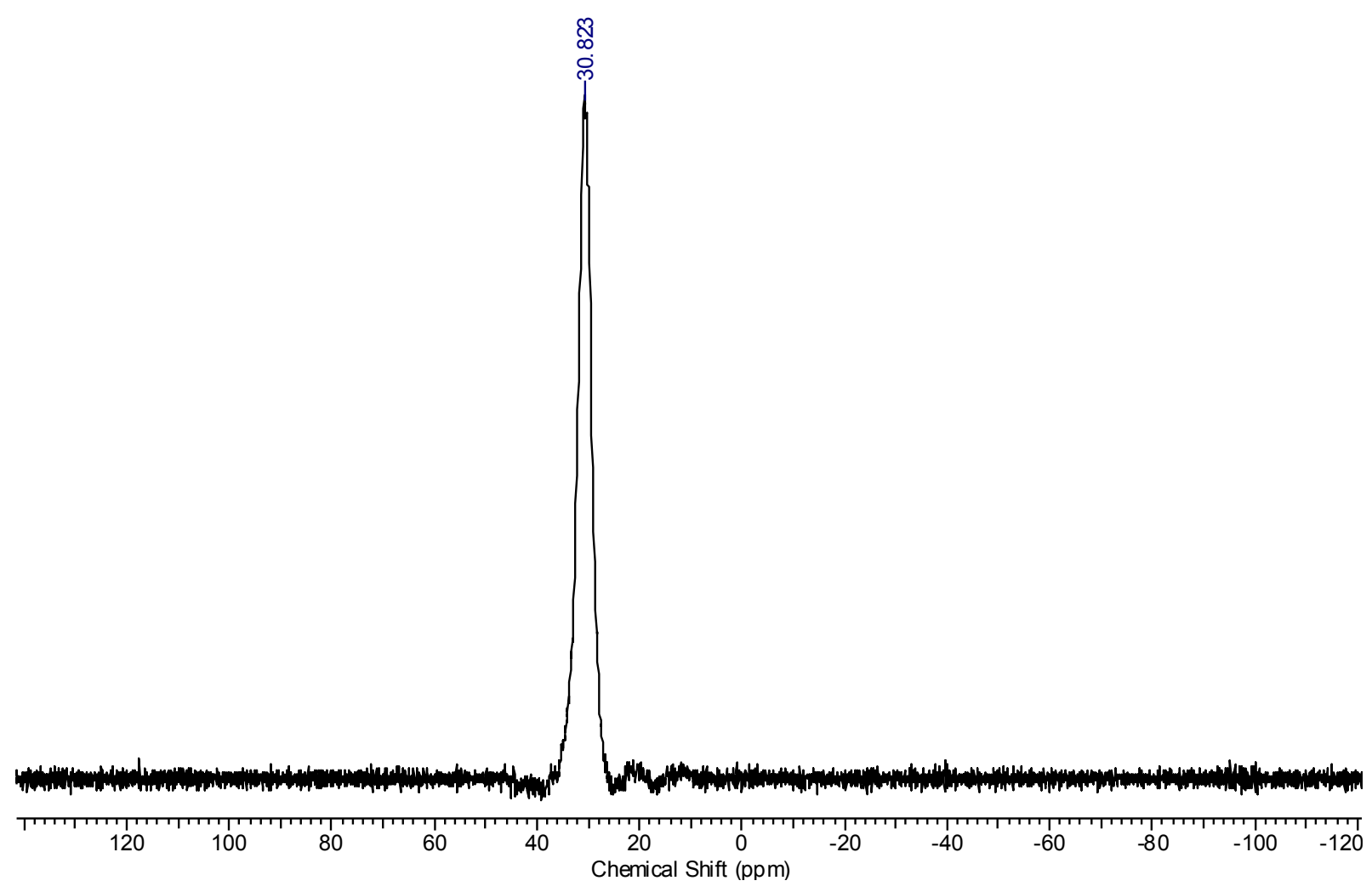


Figure S12. A) ${ }^{1} \mathrm{H}$ NMR Spectrum of a Mixture of BSe and 2BSe in $\mathrm{CDCl}_{3}$

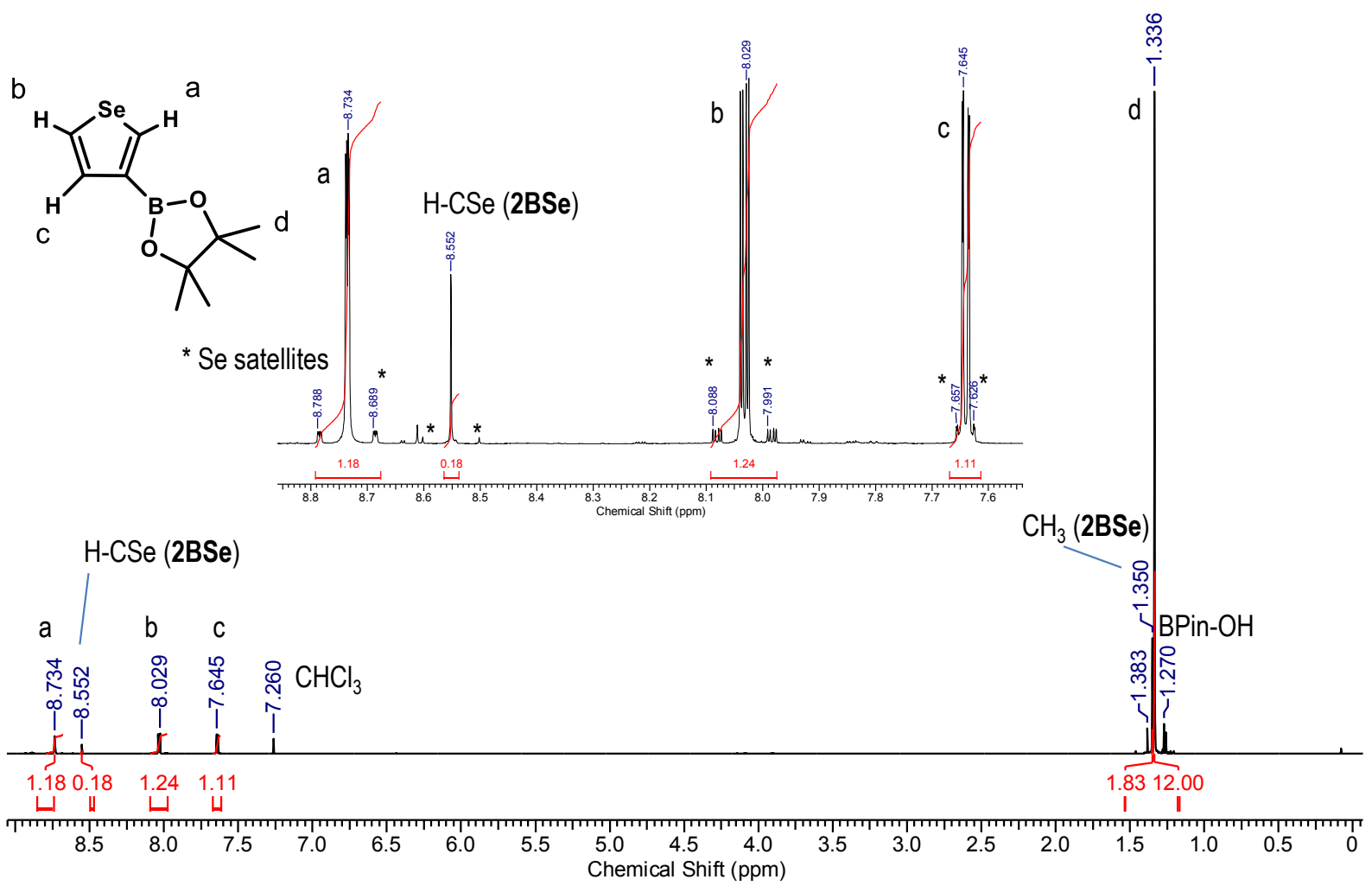

Figure S12. B) ${ }^{13} \mathrm{C}\left\{{ }^{1} \mathrm{H}\right\}$ NMR Spectrum of a Mixture of BSe and $\mathbf{2 B S e}$ in $\mathrm{CDCl}_{3}$

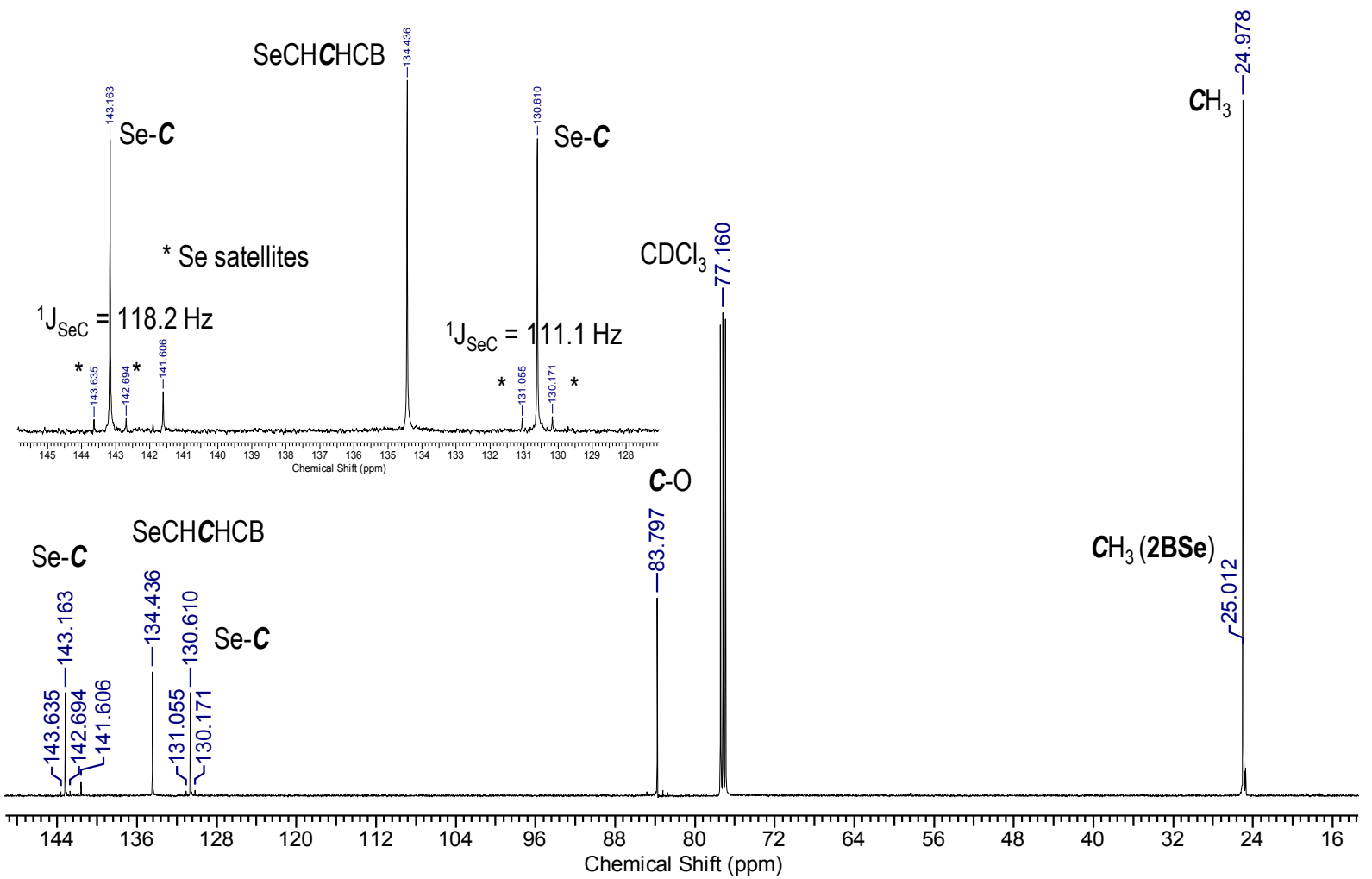


Figure S12. C) ${ }^{11} \mathrm{~B}\left\{{ }^{1} \mathrm{H}\right\}$ NMR Spectrum of BSe and $\mathbf{2 B S e}$ in $\mathrm{CDCl}_{3}$

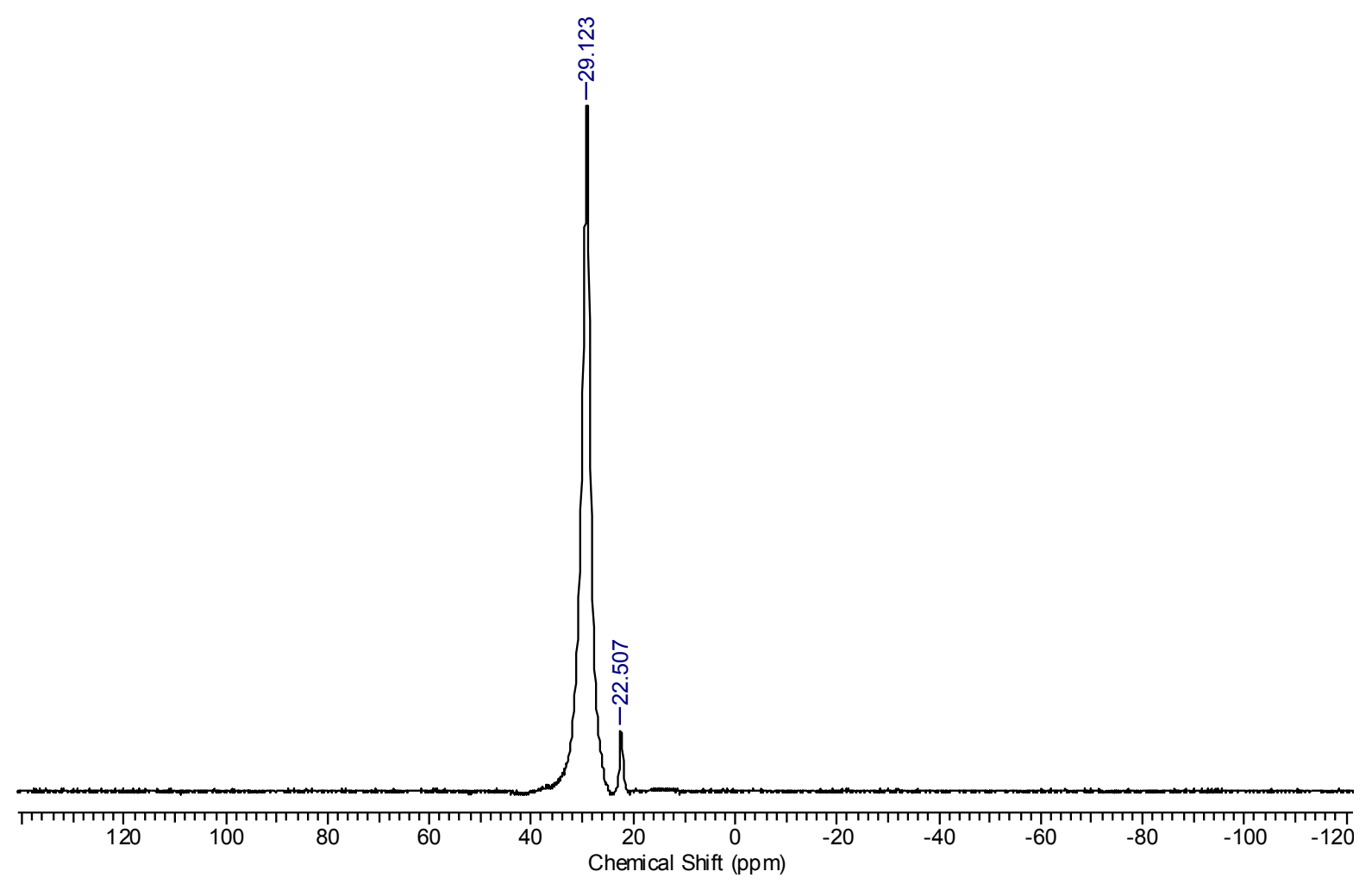


Figure S13. A) ${ }^{1} \mathrm{H}$ NMR Spectrum of T-Te-6-T in $\mathrm{CDCl}_{3}$

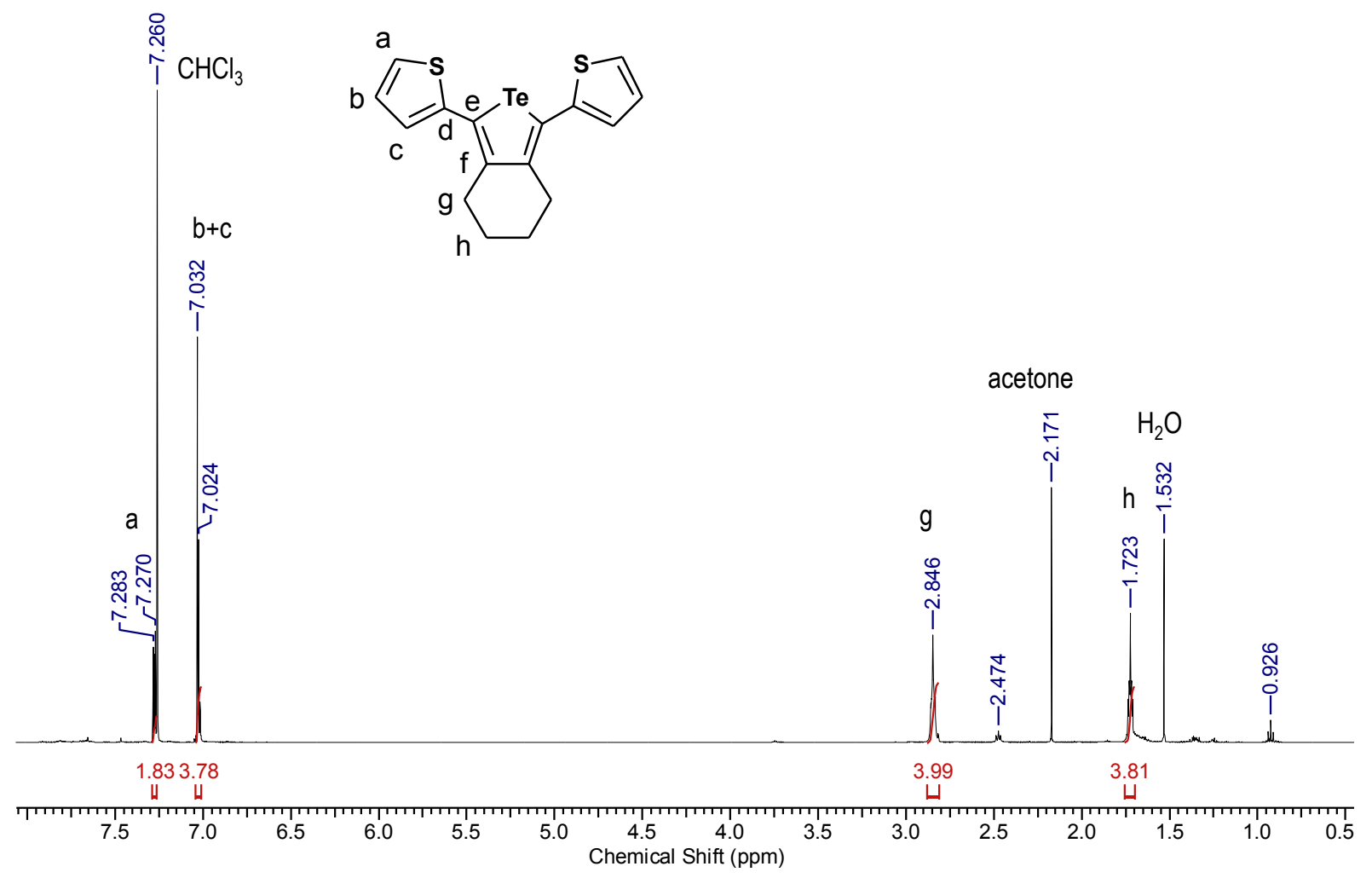

Figure S13. B) ${ }^{13} \mathrm{C}\left\{{ }^{1} \mathrm{H}\right\}$ NMR Spectrum of T-Te-6-T in $\mathrm{CDCl}_{3}$

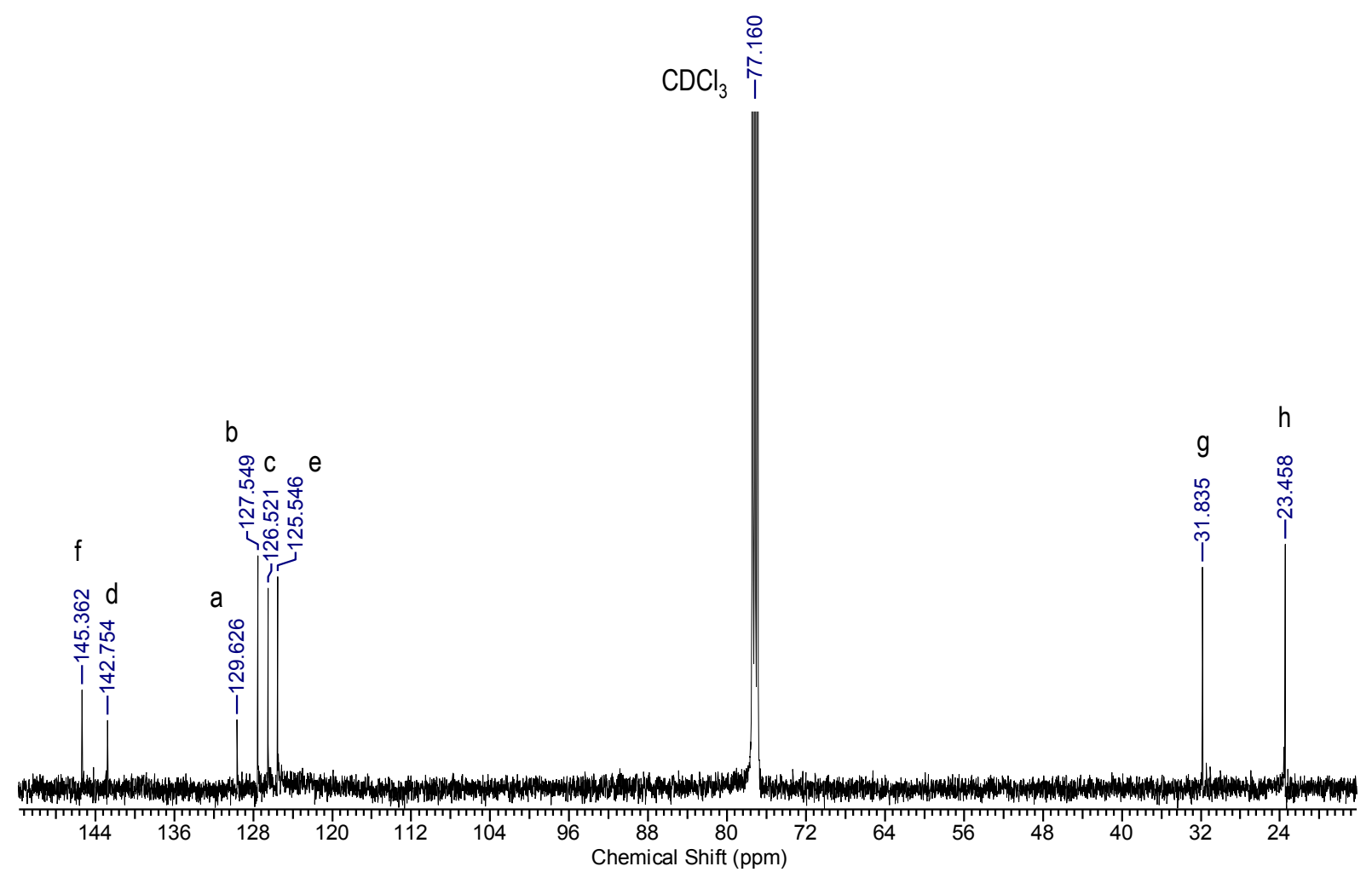


Figure S14. ${ }^{1} \mathrm{H}$ NMR Spectrum of a Reaction Mixture containing $\mathrm{BrBTe}$ and $\mathbf{2 B r T e}$ in $\mathrm{CDCl}_{3}$

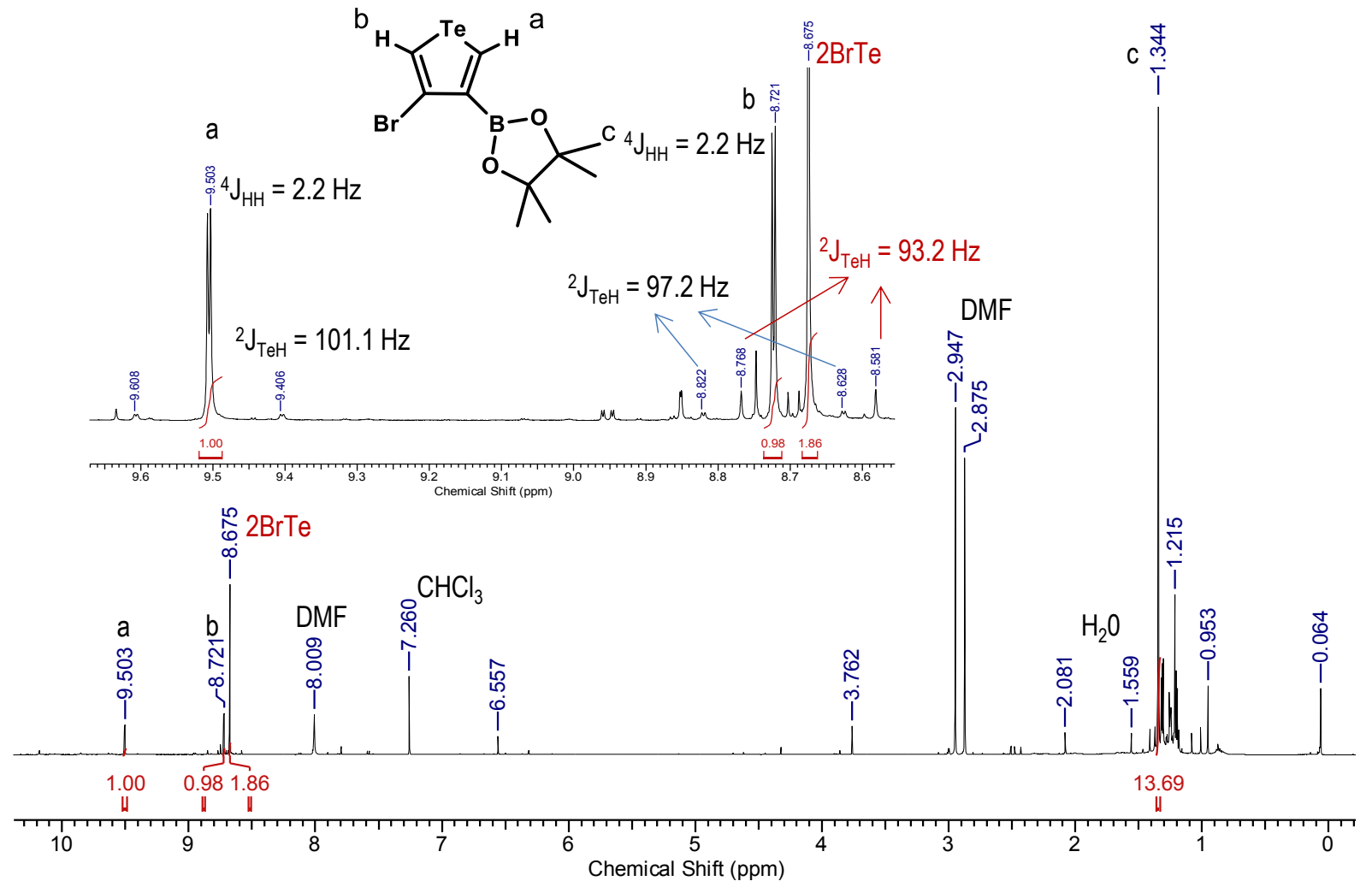

Figure S15. ${ }^{1} \mathrm{H}$ NMR Spectrum of a Reaction Mixture containing 3BTe and 2BTe in $\mathrm{CDCl}_{3}$
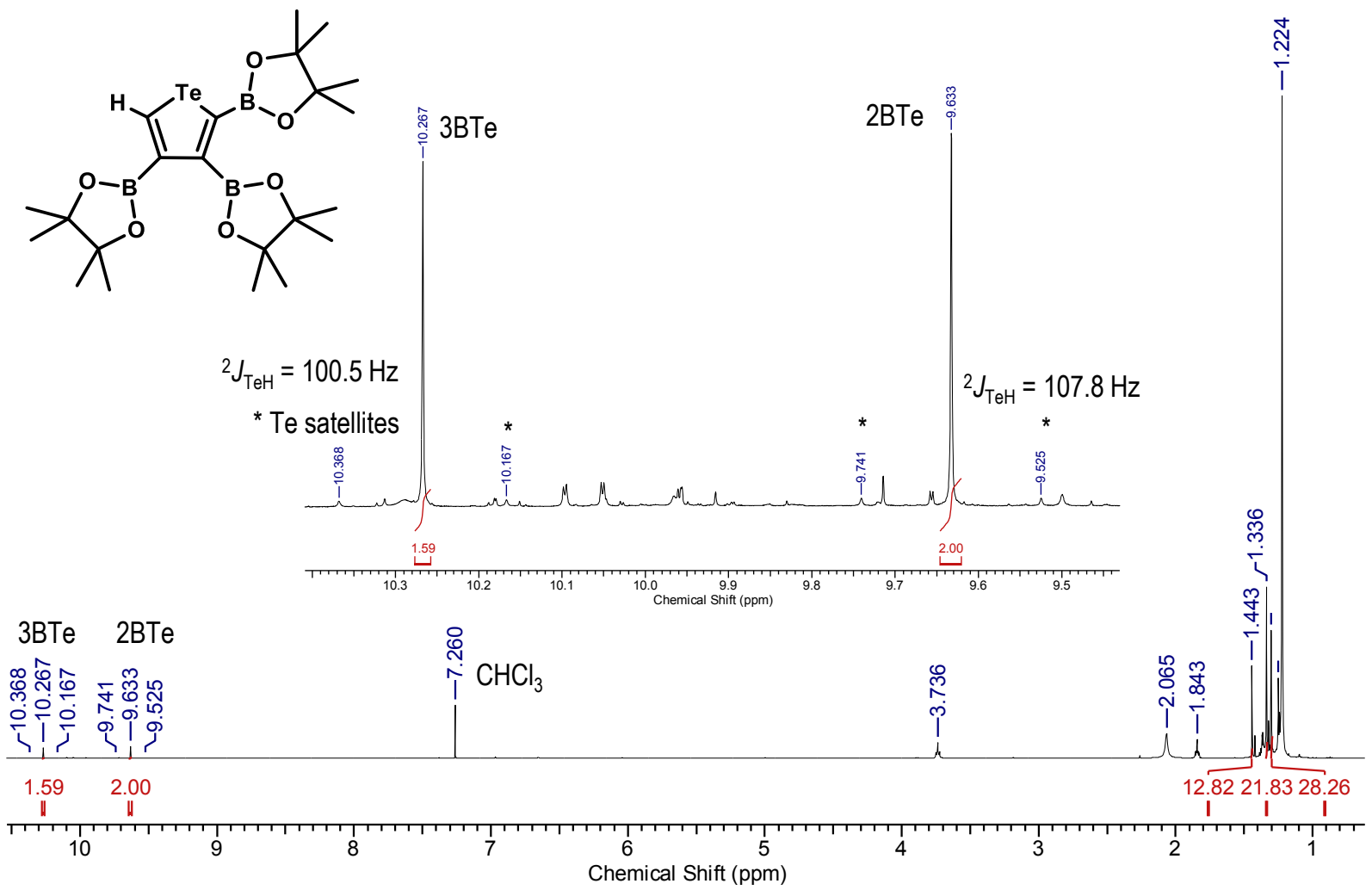
Figure S16. A) ${ }^{1} \mathrm{H}$ NMR Spectrum of B-Te6-B in $\mathrm{CDCl}_{3}$
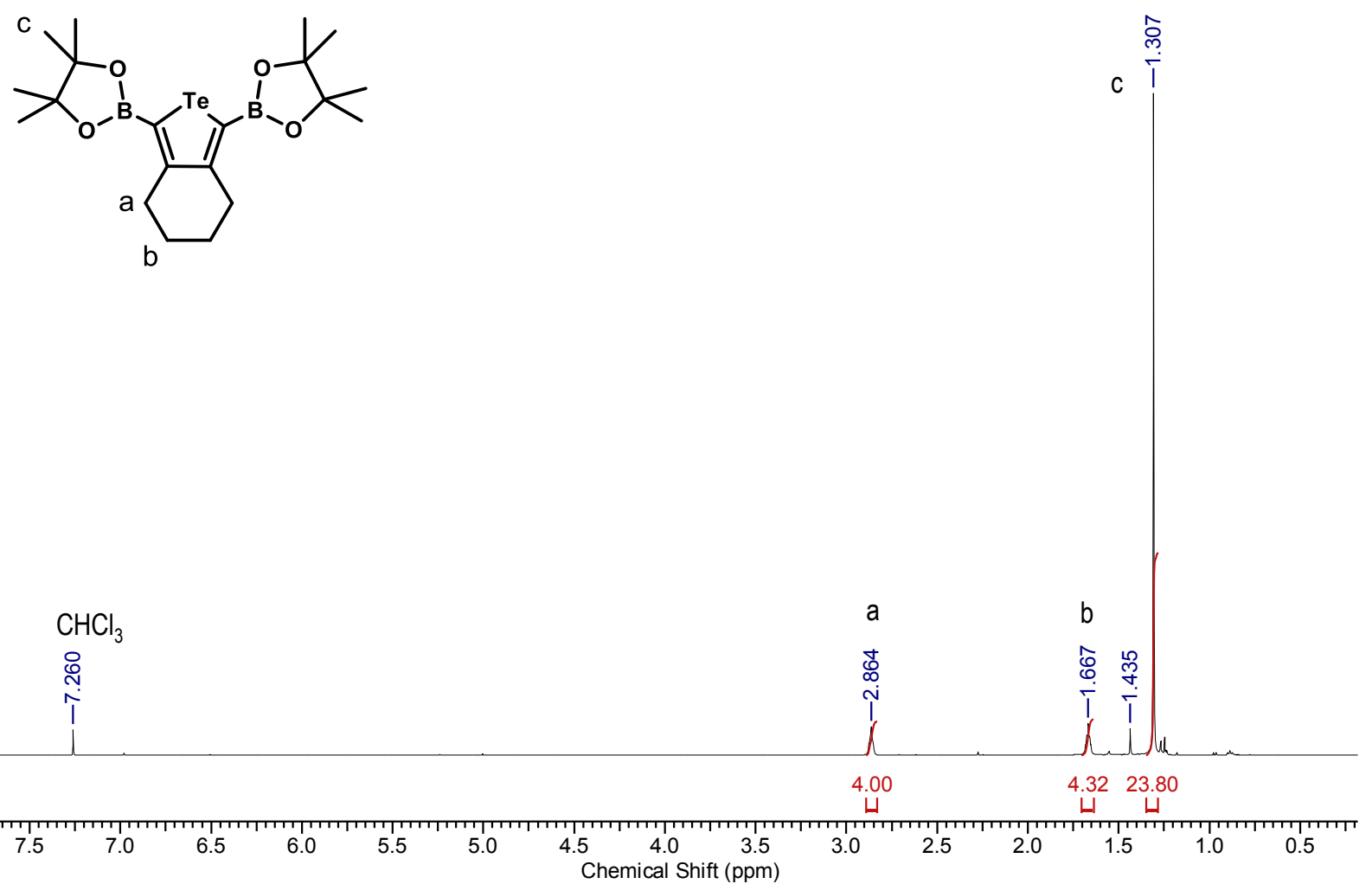

Figure S16. B) ${ }^{13} C\left\{{ }^{1} \mathrm{H}\right\}$ NMR Spectra of B-Te6-B in $\mathrm{CDCl}_{3}$

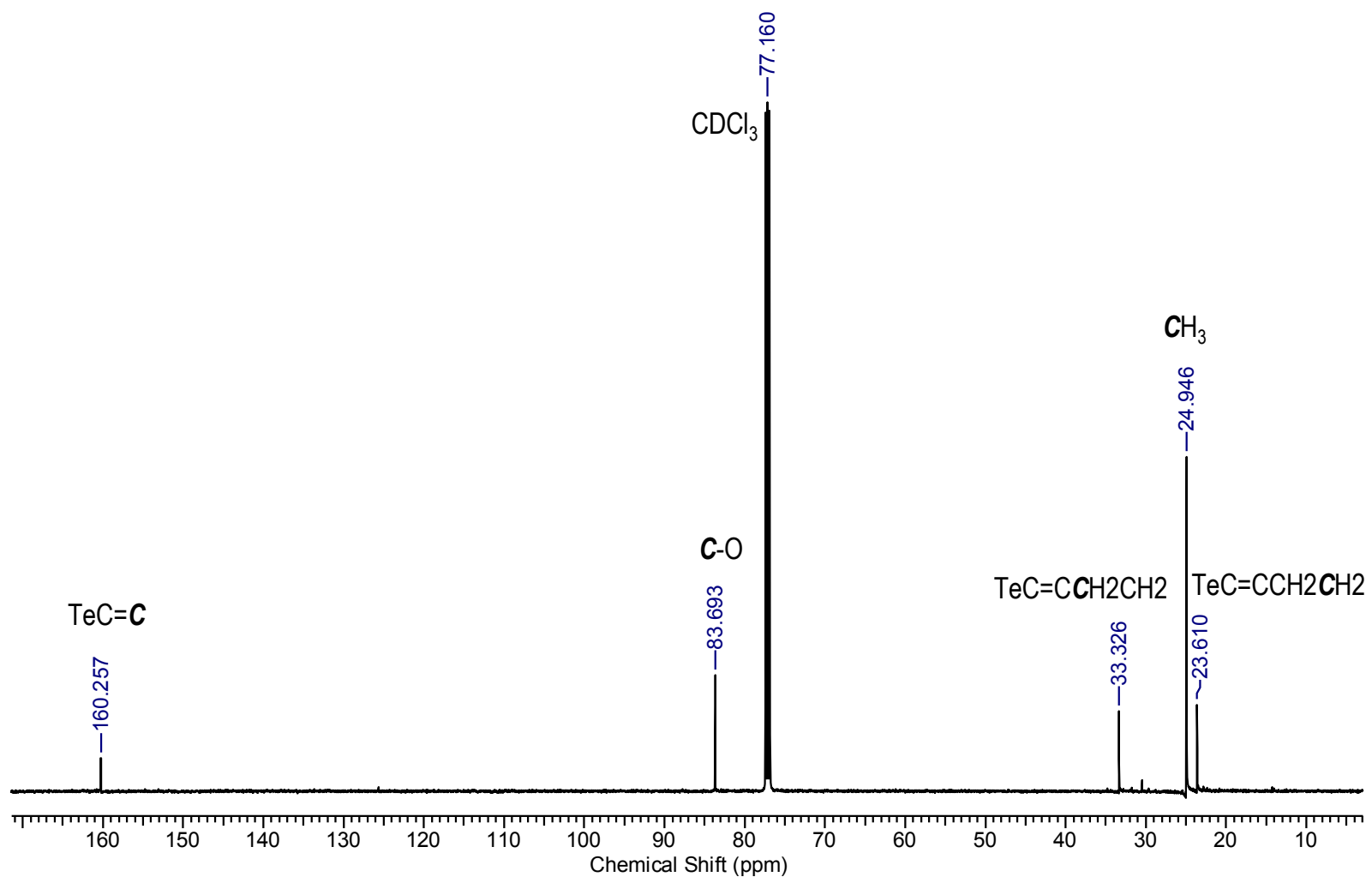


Figure S16. C) ${ }^{11} \mathrm{~B}\left\{{ }^{1} \mathrm{H}\right\}$ NMR Spectrum of B-Te6-B in $\mathrm{CDCl}_{3}$

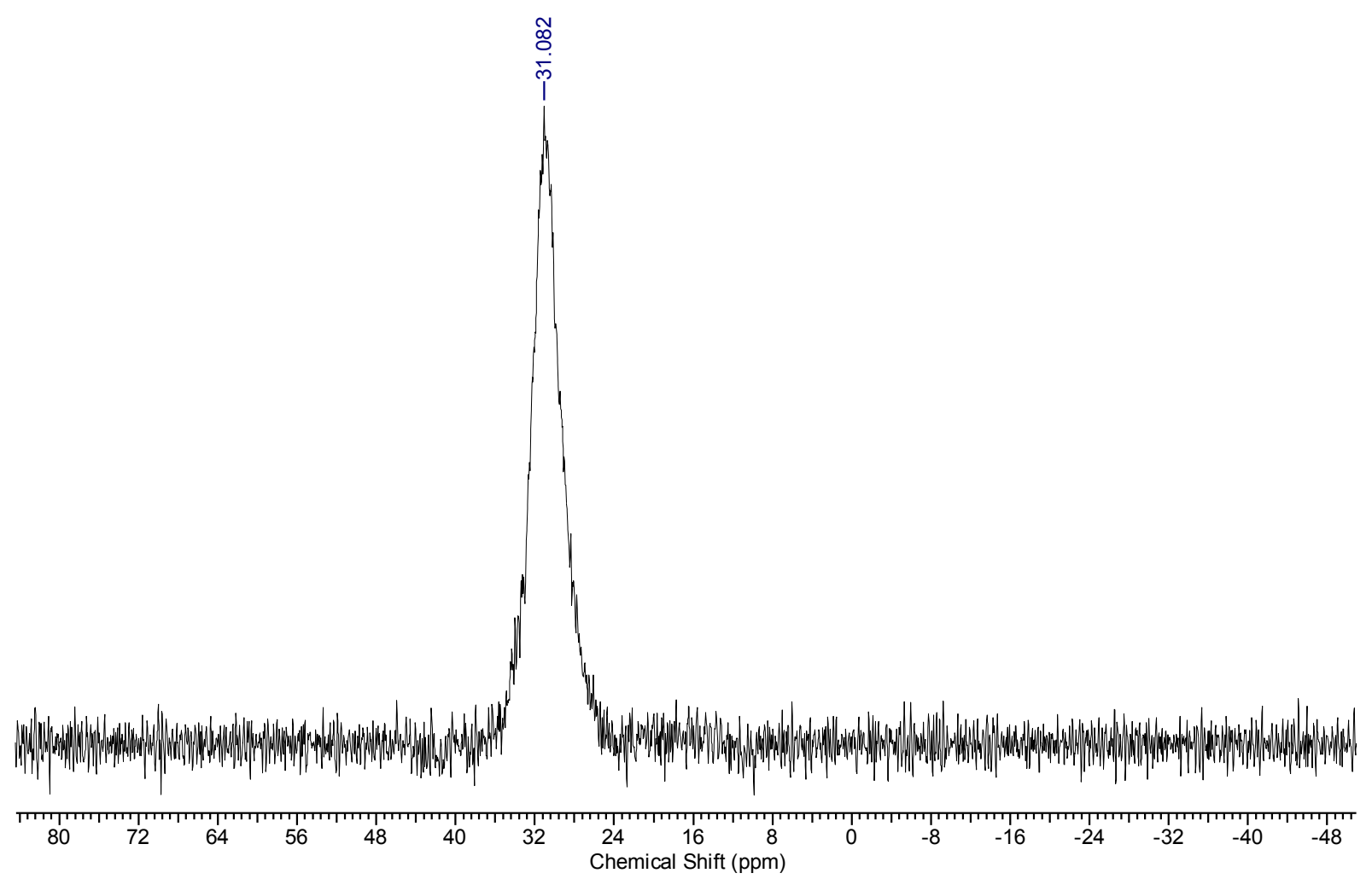


Figure S17. A) ${ }^{1} \mathrm{H}$ NMR Spectrum of 4BTe in $\mathrm{CDCl}_{3}$<smiles></smiles>

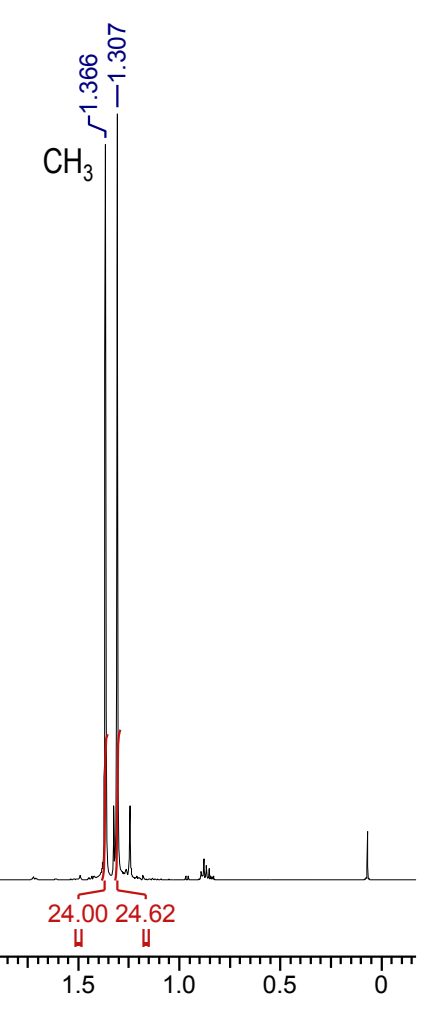

Figure S17. B) ${ }^{13} \mathrm{C}\left\{{ }^{1} \mathrm{H}\right\}$ NMR Spectrum of 4BTe in $\mathrm{CDCl}_{3}$

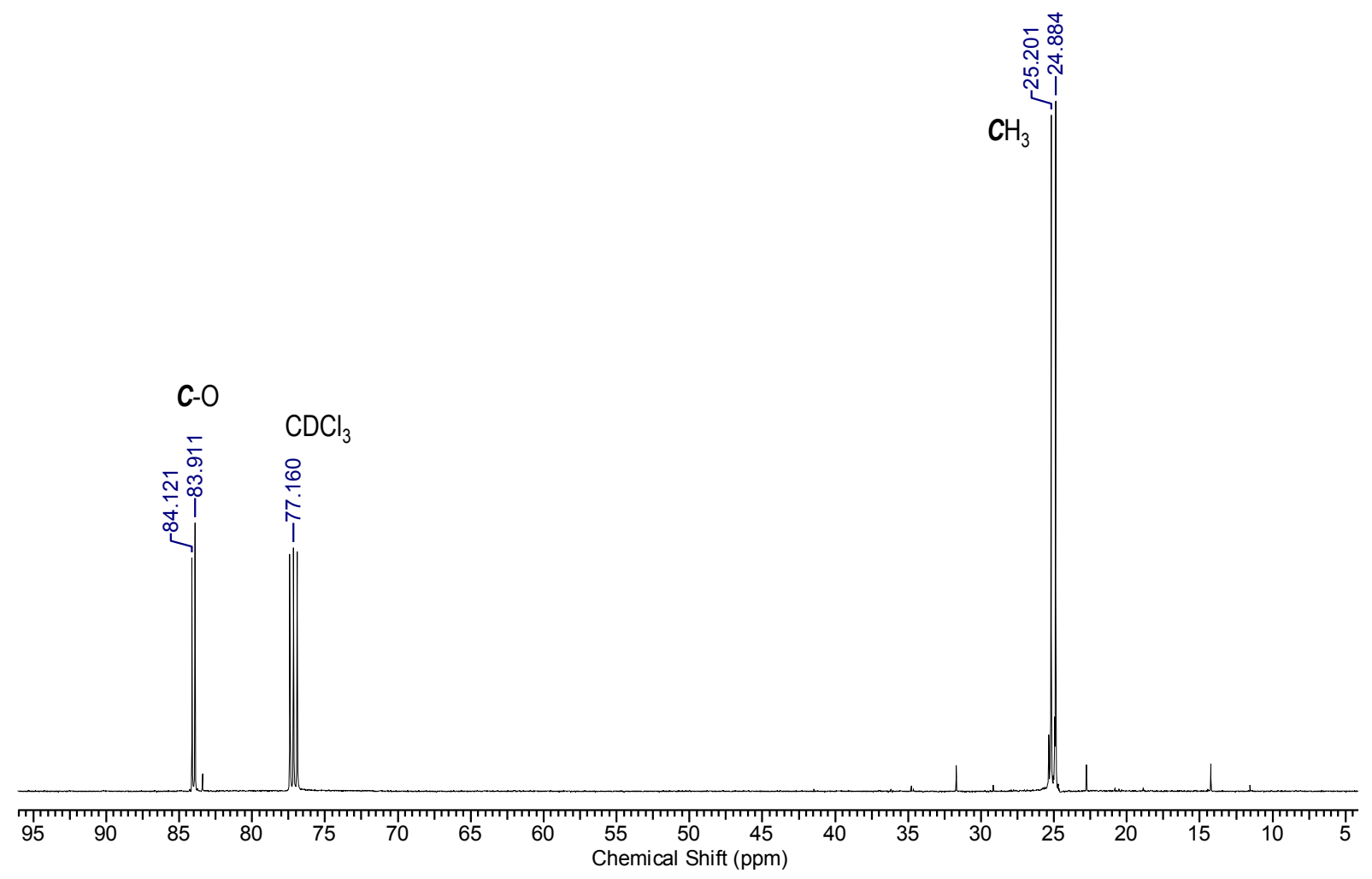


Figure S17. C) ${ }^{11} \mathrm{~B}\left\{{ }^{1} \mathrm{H}\right\}$ NMR Spectrum of $4 \mathrm{BTe}$ in $\mathrm{CDCl}_{3}$

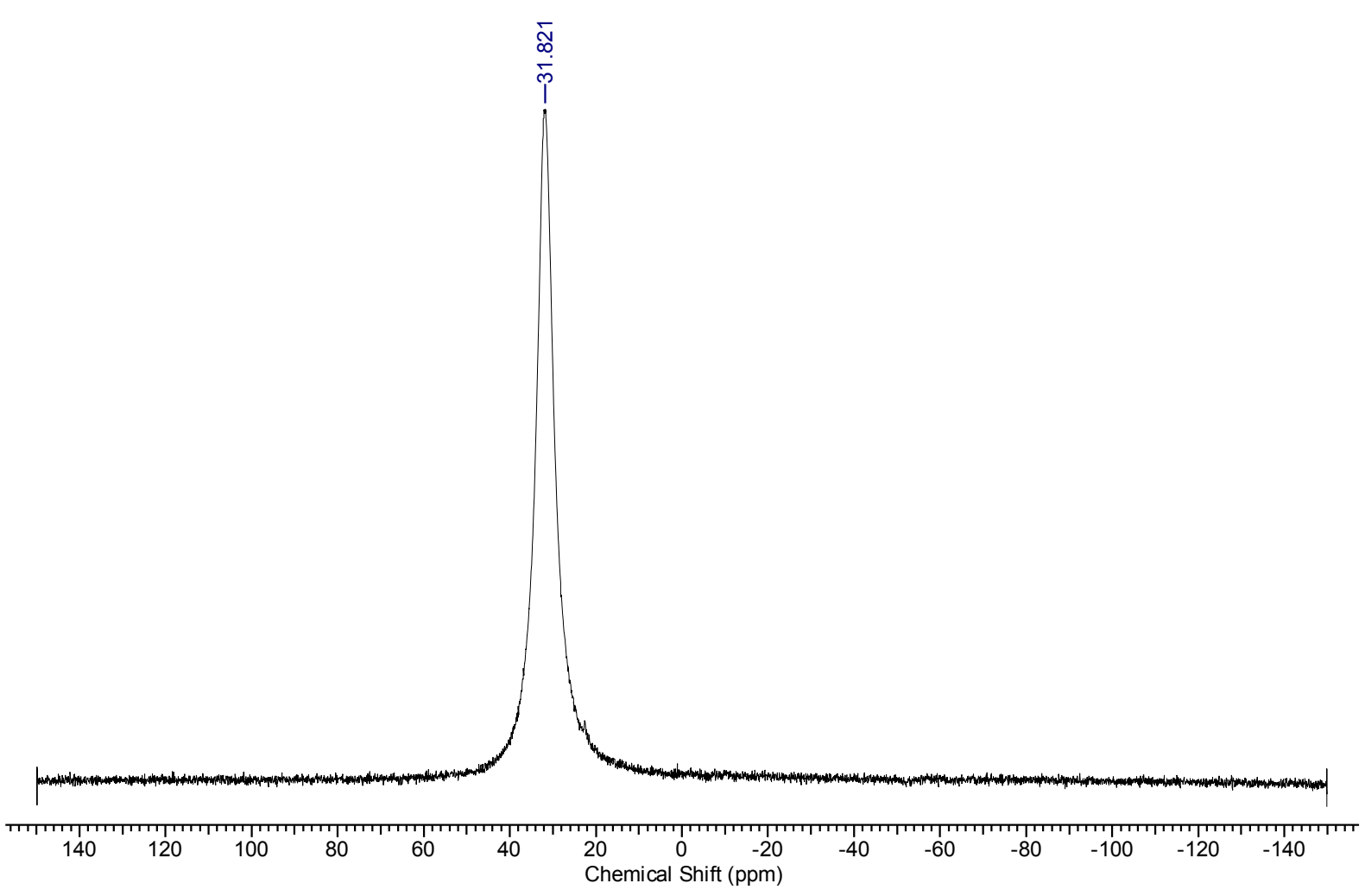


2. Table S1. X-Ray Crystallographic Data for BTe

\section{A. Crystal Data}

formula

formula weight

crystal dimensions ( $\mathrm{mm}$ )

crystal system

space group

unit cell parameters $^{a}$

$a(\AA)$

$c(\AA)$

$V\left(\AA^{3}\right)$

Z

$\rho_{\text {calcd }}\left(\mathrm{g} \mathrm{cm}^{-3}\right)$

$\mu\left(\mathrm{mm}^{-1}\right)$

\section{B. Data Collection and Refinement Conditions}

diffractometer

radiation $(\lambda[\AA]])$

temperature $\left({ }^{\circ} \mathrm{C}\right)$

scan type

data collection $2 \theta$ limit (deg)

total data collected

independent reflections

number of observed reflections (NO)

structure solution method

refinement method
$\mathrm{C}_{10} \mathrm{H}_{15} \mathrm{BO}_{2} \mathrm{Te}$

305.63

$0.28 \times 0.27 \times 0.14$

tetragonal

$14_{1} / a($ No. 88$)$

$14.2559(6)$

$23.5690(10)$

$4789.9(5)$

16

1.695

2.457

Bruker D8/APEX II CCD $b$

graphite-monochromated Mo K $\alpha(0.71073)$

$-100$

$\omega$ scans $\left(0.3^{\circ}\right)(20 \mathrm{~s}$ exposures)

57.43

$38423(-19 \leq h \leq 19,-19 \leq k \leq 19,-31 \leq 1 \leq 31)$

$3007\left(R_{\text {int }}=0.0194\right)$

$2856\left[F_{0}^{2} \geq 2 \sigma\left(F_{0}^{2}\right)\right]$

intrinsic phasing $\left(S H E L X T^{C}\right)$

full-matrix least-squares on $F^{2}$ (SHELXL-2013') 
absorption correction method

range of transmission factors

data/restraints/parameters

goodness-of-fit $(S)^{e}$ [all data]

finalRindices $f$

$$
\begin{aligned}
& R_{1}\left[F_{\mathrm{O}}^{2} \geq 2 \sigma\left(F_{\mathrm{O}}^{2}\right)\right] \\
& w R_{2} \text { [all data] }
\end{aligned}
$$

largest difference peak and hole
Gaussian integration (face-indexed)

$0.8166-0.5902$

$3007 / 24^{d} / 199$

1.085

0.0183

0.0461

0.733 and -0.306 e $\AA^{-3}$

${ }^{a}$ Obtained from least-squares refinement of 9769 reflections with $5.32^{\circ}<2 \theta<57.12^{\circ}$.

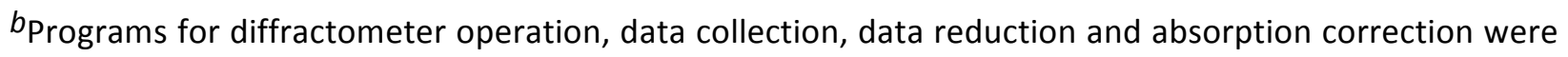
those supplied by Bruker.

CSheldrick, G. M. ActaCrystallogr.2008, A64, 112-122.

${ }^{d}$ The $\mathrm{C}-\mathrm{C}$, the $\mathrm{O}-\mathrm{C}$ and the $\mathrm{O}-\mathrm{B}$ sets of distances within the disordered tetramethyldioxaborolane group were restrained to be the same by use of the SHELXLSADI instruction. Additionally, a rigid-bond restraint was applied to the anisotropic displacement parameters of the carbon atoms of the minor component by use of the SHELXLDELU instruction.

$$
\begin{aligned}
e S= & {\left[\Sigma w\left(F_{\mathrm{O}}^{2}-F_{\mathrm{C}}^{2}\right)^{2} /(n-p)\right]^{1 / 2}\left(n=\text { number of data; } p=\text { number of parameters varied; } w=\left[\sigma^{2}\left(F_{\mathrm{O}}^{2}\right)+\right.\right.} \\
& \left.\left.(0.0225 P)^{2}+5.6607 P\right]^{-1} \text { where } P=\left[\operatorname{Max}\left(F_{\mathrm{O}}^{2}, 0\right)+2 F_{\mathrm{C}}^{2}\right] / 3\right) . \\
f_{R_{1}}= & \Sigma|| F_{\mathrm{O}}|-| F_{\mathrm{C}}|| / \Sigma\left|F_{\mathrm{O}}\right| ; w R_{2}=\left[\Sigma w\left(F_{\mathrm{O}}^{2}-F_{\mathrm{C}}^{2}\right)^{2} / \Sigma w\left(F_{\mathrm{O}}{ }^{4}\right)\right]^{1 / 2} .
\end{aligned}
$$


3. Table S2. X-Ray Crystallographic Data for B-Te-6-H

\section{A. Crystal Data}

formula

formula weight

crystal dimensions $(\mathrm{mm})$

crystal system

space group

unit cell parameters $^{a}$

$$
\begin{aligned}
& a(\AA ̊) \\
& c(\AA ̊) \\
& V\left(\AA^{3}\right)
\end{aligned}
$$

\section{Z}

$\rho_{\text {calcd }}\left(\mathrm{g} \mathrm{cm}^{-3}\right)$

$\mu\left(\mathrm{mm}^{-1}\right)$

\section{B. Data Collection and Refinement Conditions}

diffractometer

radiation $(\lambda[\AA]])$

temperature $\left({ }^{\circ} \mathrm{C}\right)$

scan type

data collection $2 \theta$ limit (deg)

total data collected

independent reflections

number of observed reflections (NO)

structure solution method

refinement method
$\mathrm{C}_{14} \mathrm{H}_{21} \mathrm{BO}_{2} \mathrm{Te}$

359.72

$0.30 \times 0.27 \times 0.19$

tetragonal

$P 4_{3} 2_{1} 2$ (No. 96)

$9.1615(2)$

36.3296 (10)

$3049.27(18)$

8

1.567

15.32

Bruker D8/APEX $\| C^{C} D^{b}$

Cu K $\alpha$ (1.54178) (microfocus source)

$-100$

$\omega$ and $\phi$ scans $\left(1.0^{\circ}\right)$ (5 s exposures)

148.12

$21409(-10 \leq h \leq 11,-11 \leq k \leq 11,-45 \leq l \leq 45)$

$3103\left(R_{\text {int }}=0.0436\right)$

$3090\left[F_{\mathrm{O}}^{2} \geq 2 \sigma\left(F_{\mathrm{O}}^{2}\right)\right]$

Patterson/structure expansion (DIRDIF-2008 ${ }^{C}$ )

full-matrix least-squares on $F^{2}$ (SHELXL-2014d) 


$\begin{array}{ll}\text { absorption correction method } & \text { Gaussian integration (face-indexed) } \\ \text { range of transmission factors } & 0.2778-0.0477 \\ \text { data/restraints/parameters } & 3103 / 0 / 182 \\ \text { Flack absolute structure parameter } & 0.060(9) \\ \text { goodness-of-fit }(S) \text { [all data] } & 1.068 \\ \text { final } R \text { indices } g & \\ R_{1}\left[F_{\mathrm{O}}{ }^{2} \geq 2 \sigma\left(F_{\mathrm{O}}{ }^{2}\right)\right] & 0.0226 \\ \quad W R_{2} \text { [all data] } & 0.0563 \\ \text { largest difference peak and hole } & 0.434 \text { and }-1.102 \text { e } \AA^{-3}\end{array}$

${ }^{a}$ Obtained from least-squares refinement of 9177 reflections with $4.86^{\circ}<2 \theta<147.34^{\circ}$.

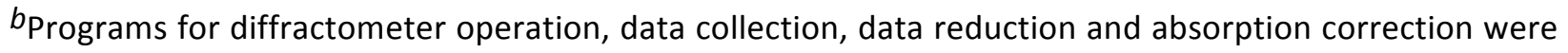
those supplied by Bruker.

${ }^{C_{B} B e u r s k e n s, ~ P . ~ T . ; ~ B e u r s k e n s, ~ G . ; ~ d e ~ G e l d e r, ~ R . ; ~ S m i t s, ~ J . ~ M . ~ M . ; ~ G a r c i a-G r a n d a, ~ S . ; ~ G o u l d, ~ R . ~ O . ~(2008) . ~}$ The DIRDIF-2008 program system. Crystallography Laboratory, RadboudUniversityNijmegen, The Netherlands.

dSheldrick, G. M. ActaCrystallogr.2015, C71, 3-8.

eFlack, H. D. Acta Crystallogr.1983, A39, 876-881; Flack, H. D.; Bernardinelli, G. ActaCrystallogr.1999, A55, 908-915; Flack, H. D.; Bernardinelli, G. J. Appl. Cryst.2000, 33, 1143-1148. The Flack parameter will refine to a value near zero if the structure is in the correct configuration and will refine to a value near one for the inverted configuration.

$f_{S}=\left[\Sigma w\left(F_{\mathrm{O}}{ }^{2}-{F_{\mathrm{C}}}^{2}\right)^{2} /(n-p)\right]^{1 / 2}\left(n=\right.$ number of data; $p=$ number of parameters varied; $w=\left[\sigma^{2}\left(F_{\mathrm{O}}{ }^{2}\right)+\right.$ $\left.(0.0249 P)^{2}+2.8836 P\right]^{-1}$ where $\left.P=\left[\operatorname{Max}\left(F_{\mathrm{O}}{ }^{2}, 0\right)+2 F_{\mathrm{C}}{ }^{2}\right] / 3\right)$.

$g_{R_{1}}=\Sigma|| F_{\mathrm{o}}|-| F_{\mathrm{c}}|| / \Sigma\left|F_{\mathrm{O}}\right| ; w R_{2}=\left[\Sigma w\left(F_{\mathrm{o}}^{2}-{F_{\mathrm{c}}}^{2}\right)^{2} / \Sigma w\left(F_{\mathrm{o}}^{4}\right)\right]^{1 / 2}$. 


\section{Crystallographic Information for 4BSe}

Figure S16. Molecular Structure of 4BSe with Ellipsoids at a $30 \%$ Probability Level. All Hydrogen atoms have been omitted for clarity. Selected bond lengths $(\AA)$ and angles $\left({ }^{\circ}\right)$ : $C(1)-C(2) 1.374(4), C(2)-C(3)$ 1.453(3), C(3)-C(4) 1.378(4), C(1)-B(1) 1.544(4), C(2)-B(2) 1.573(4), C(3)-B(3) 1.555(4), C(4)-B(4) 1.561(4), $C(1)$-Se 1.876(3), $C(4)-S e$ 1.864(2); $C(1)-S e-C(4)$ 88.52(11), $C(1)-C(2)-C(3) 114.6(2) C(2)-C(3)-C(4) 115.1(2)$, $C(2)-C(1)-S e$ 110.90(17), $C(3)-C(4)-S e$ 110.82(17), Se-C(1)-B(1) 120.9(2), Se-C(4)-B(4) 121.65(19), $C(1)-$ $B(1)-O(1) 124.4(3), C(2)-B(2)-O(3) 124.2(3), C(3)-B(3)-O(5) 123.1(3), C(4)-B(4)-O(7) 121.8(2)$.

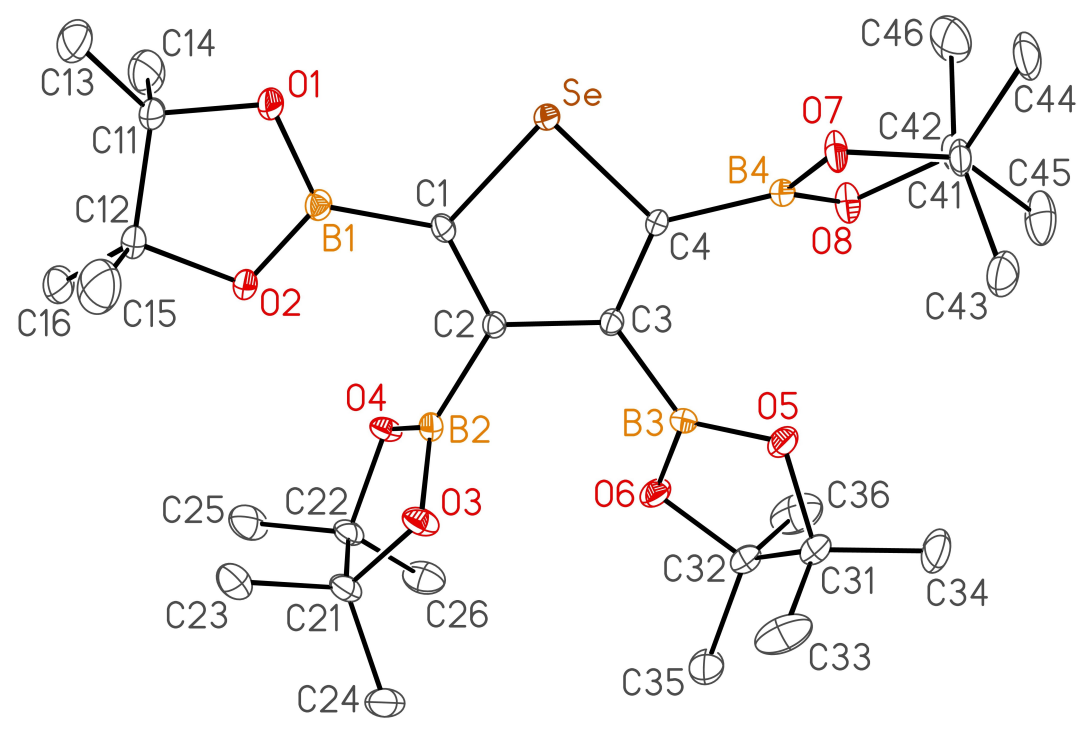

Table S3. Crystallographic Data for 4BSe

\section{A. Crystal Data}

formula

formula weight

crystal dimensions ( $\mathrm{mm}$ )

crystal system

space group

unit cell parameters $a$
$\mathrm{C}_{28} \mathrm{H}_{48} \mathrm{~B}_{4} \mathrm{O}_{8} \mathrm{Se}$

634.86

$0.40 \times 0.31 \times 0.30$

monoclinic

$P 21$ (No. 4) 


\begin{tabular}{|c|c|}
\hline$a(\AA)$ & $10.4690(11)$ \\
\hline$b(\AA)$ & $13.8325(14)$ \\
\hline$c(\AA)$ & $11.9952(12)$ \\
\hline$\beta$ (deg) & $100.7232(11)$ \\
\hline$V\left(\AA^{3}\right)$ & $1706.7(3)$ \\
\hline$Z$ & 2 \\
\hline$\rho_{\text {calcd }}\left(\mathrm{g} \mathrm{cm}^{-3}\right)$ & 1.235 \\
\hline$\mu\left(\mathrm{mm}^{-1}\right)$ & 1.142 \\
\hline \multicolumn{2}{|c|}{ B. Data Collection and Refinement Conditions } \\
\hline diffractometer & Bruker D8/APEX II CCD ${ }^{b}$ \\
\hline radiation $(\lambda[\AA]])$ & graphite-monochromated Mo K $\alpha(0.71073)$ \\
\hline temperature $\left({ }^{\circ} \mathrm{C}\right)$ & -100 \\
\hline scan type & $\omega$ scans $\left(0.4^{\circ}\right)(10 \mathrm{~s}$ exposures $)$ \\
\hline data collection $2 \theta$ limit (deg) & 55.16 \\
\hline total data collected & $39904(-13 \leq h \leq 13,-17 \leq k \leq 17,-15 \leq l \leq 15)$ \\
\hline independent reflections & $7793\left(R_{\text {int }}=0.0306\right)$ \\
\hline number of observed reflections (NO) & $7534\left[F_{\mathrm{o}}^{2} \geq 2 \sigma\left(F_{\mathrm{O}}^{2}\right)\right]$ \\
\hline structure solution method & Patterson/structure expansion (DIRDIF-2008C) \\
\hline refinement method & full-matrix least-squares on $F^{2}\left(S H E L X L-2013^{d}\right)$ \\
\hline absorption correction method & multi-scan (TWINABS) \\
\hline range of transmission factors & $0.7923-0.7156$ \\
\hline data/restraints/parameters & 7793 / 0 / 371 \\
\hline Flack absolute structure parameter ${ }^{e}$ & $0.035(3)$ \\
\hline goodness-of-fit $(S)^{f}$ [all data] & 1.030 \\
\hline
\end{tabular}




$$
\begin{array}{cl}
R_{1}\left[F_{\mathrm{O}}^{2} \geq 2 \sigma\left(F_{\mathrm{O}}^{2}\right)\right] & 0.0264 \\
W R_{2} \text { [all data] } & 0.0668 \\
\text { largest difference peak and hole } & 0.490 \text { and }-0.791 \text { e } \AA^{-3}
\end{array}
$$

${ }^{a}$ Obtained from least-squares refinement of 9957 reflections with $4.54^{\circ}<2 \theta<55.08^{\circ}$.

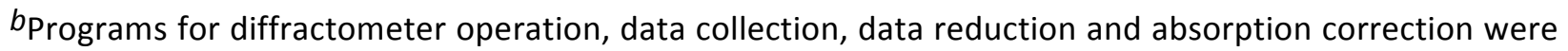
those supplied by Bruker. The crystal used for data collection was found to display non-merohedral twinning. Both components of the twin were indexed with the program CELL_NOW (Bruker AXS Inc., Madison, WI, 2004). The second twin component can be related to the first component by 180 o rotation about the $\left[\begin{array}{lll}0.2 & 0 & 1\end{array}\right]$ axis in real space and about the $\left[\begin{array}{lll}0 & 0 & 1\end{array}\right]$ axis in reciprocal space. Integrated intensities for the reflections from the two components were written into a SHELXL-2013 HKLF 5 reflection file with the data integration program SAINT (version 8.32B), using all reflection data (exactly overlapped, partially overlapped and non-overlapped). The refined value of the twin fraction (SHELXL-2013 BASF parameter) was 0.0930(6).

CBeurskens, P. T.; Beurskens, G.; de Gelder, R.; Smits, J. M. M.; Garcia-Granda, S.; Gould, R. O. (2008). The DIRDIF-2008 program system. Crystallography Laboratory, Radboud University Nijmegen, The Netherlands.

dSheldrick, G. M. Acta Crystallogr. 2008, A64, 112-122.

eFlack, H. D. Acta Crystallogr. 1983, A39, 876-881; Flack, H. D.; Bernardinelli, G. Acta Crystallogr. 1999, A55, 908-915; Flack, H. D.; Bernardinelli, G. J. Appl. Cryst. 2000, 33, 1143-1148. The Flack parameter will refine to a value near zero if the structure is in the correct configuration and will refine to a value near one for the inverted configuration.

$f_{S}=\left[\Sigma w\left(F_{\mathrm{O}}{ }^{2}-F_{\mathrm{C}}{ }^{2}\right)^{2} /(n-p)\right]^{1 / 2}\left(n=\right.$ number of data; $p=$ number of parameters varied; $w=\left[\sigma^{2}\left(F_{\mathrm{O}}{ }^{2}\right)+\right.$ $\left.(0.0391 P)^{2}+0.0327 P\right]^{-1}$ where $\left.P=\left[\operatorname{Max}\left(F_{\mathrm{O}}{ }^{2}, 0\right)+2 F_{\mathrm{C}}{ }^{2}\right] / 3\right)$.

$g_{R_{1}}=\Sigma|| F_{\mathrm{O}}|-| F_{\mathrm{c}}|| / \Sigma\left|F_{\mathrm{O}}\right| ; w R_{2}=\left[\Sigma w\left(F_{\mathrm{O}}^{2}-F_{\mathrm{c}}^{2}\right)^{2} / \Sigma w\left(F_{\mathrm{O}}^{4}\right)\right]^{1 / 2}$. 